\title{
DSM Shareholder Incentives: Current Designs and Economic Theory
}

\author{
S. Stoft, J. Eto and S. Kito \\ Energy \& Environment Division \\ Lawrence Berkeley Laboratory \\ University of California \\ Berkeley, California 94720
}

January 1995

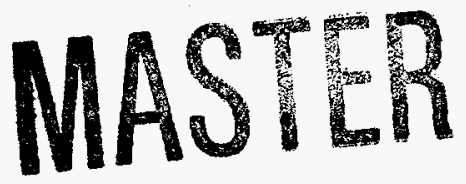

The work described in this study was funded by the Assistant Secretary of Energy Efficiency and Renewable Energy, Office of Utility Technologies, Energy Management Division of the U.S. Department of Energy under Contract No. DE-AC03$76 \mathrm{SF} 00098$. 


\section{DISCLAIMER}

This report was prepared as an account of work sponsored by an agency of the United States Government. Neither the United States Government nor any agency thereof, nor any of their employees, make any warranty, express or implied, or assumes any legal liability or responsibility for the accuracy, completeness, or usefulness of any information, apparatus, product, or process disciosed, or represents that its use would not infringe privately owned rights. Reference herein to any specific commercial product, process, or service by trade name, trademark, manufacturer, or otherwise does not necessarily constitute or imply its endorsement, recommendation, or favoring by the United States Government or any agency thereof. The views and opinions of authors expressed herein do not necessarily state or reflect those of the United States Government or any agency thereof. 


\section{DISCLAIMER}

Portions of this document may be illegible in electronic image products. Images are produced from the best available original document. 


\section{Abstract}

This report reviews recent DSM shareholder incentive designs and performance at 10 U.S. utilities and identifies opportunities for regulators to improve the design of DSM shareholder incentive mechanisms to increase the procurement of cost-effective DSM resources. We develop six recommendations: (1) apply shared-savings incentives to DSM resource programs; (2) use markup incentives for individual programs only when net benefits are difficult to measure, but are known to be positive; (3) set expected incentive payments based on covering a utility's "hidden costs," which include some transitional management and riskadjusted opportunity costs; (4) use higher marginal incentives rates than are currently found in practice, but limit total incentive payments by adding a fixed charge; (5) mitigate risks to regulators and utilities by lowering marginal incentive rates at high and low performance levels; and (6) use an aggregate incentive mechanism for all DSM resource programs, with limited exceptions (e.g., information programs where markups are more appropriate). 


\section{Contents}

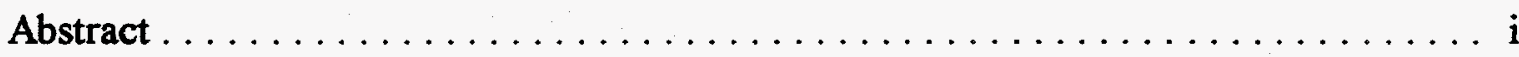

Acknowledgments $\ldots \ldots \ldots \ldots \ldots \ldots \ldots \ldots \ldots \ldots \ldots \ldots \ldots \ldots \ldots \ldots \ldots \ldots$ ix

Acronyms and Abbreviations $\ldots \ldots \ldots \ldots \ldots \ldots \ldots \ldots \ldots \ldots \ldots \ldots \ldots \ldots \ldots$

Executive Summary $\ldots \ldots \ldots \ldots \ldots \ldots \ldots \ldots \ldots \ldots \ldots \ldots \ldots \ldots \ldots \ldots \ldots \ldots \ldots$ xiii

Chapter 1: Introduction $\ldots \ldots \ldots \ldots \ldots \ldots \ldots \ldots \ldots \ldots \ldots \ldots \ldots \ldots \ldots \ldots \ldots$

Chapter 2: Ten Utility DSM Shareholder Incentives $\ldots \ldots \ldots \ldots \ldots \ldots \ldots \ldots$

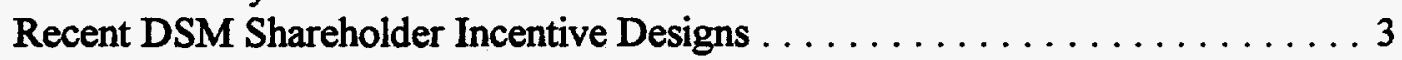

DSM Spending and Shareholder Incentive Earnings ............ 5

A Typology of DSM Shareholder Incentive Design Elements .......... 7

Chapter 3: Evaluating Overall Designs for DSM Shareholder Incentives $\ldots \ldots \ldots \ldots 9$

A Classification Scheme for DSM Shareholder Incentive Designs . . . . . . . . 9

Use of Bonus Mechanisms Requires TRC Constraints to Ensure IRP

Objectives Are Met ....................... 10

Shared Savings Mechanisms Provide Superior IRP Incentives,

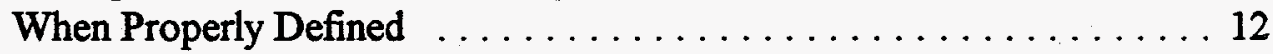

Why the Markup Mechanism Is Dangerous, but Sometimes Appropriate . . . 15

Hybrid Incentives Reflect Multiple Regulatory Objectives $\ldots \ldots \ldots \ldots \ldots$

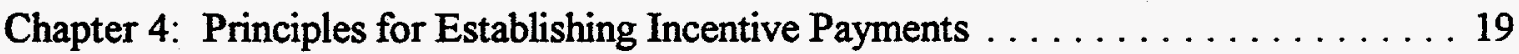

Current Practice Varies Considerably . . . . . . . . . . . . . . . 19

The Crucial Role of Unobservable (Hidden) Costs $\ldots \ldots \ldots \ldots \ldots \ldots 20$

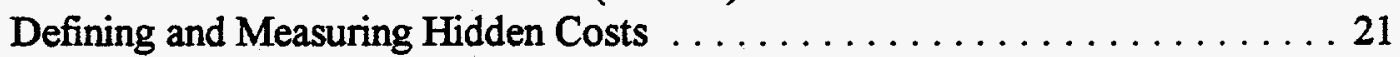

Review of Current Trends in Establishing Incentive Payments $\ldots \ldots \ldots \ldots 23$

Chapter 5: The Importance of Marginal Incentive Rates $\ldots \ldots \ldots \ldots \ldots \ldots 25$

A Comparison of Shared Savings Marginal Incentive Rates . . . . . . . 25

Marginal Incentive Rates Determine Performance ............. 29

A Recent Example of a Marginal Incentive Rate that Was Too High . . . . 30

The Optimal Marginal Incentive Rate Is 100 Percent ............. 34

Decoupling Marginal Incentive Rates from the Total Incentive Payment . . . . 36

Chapter 6: Mitigating Risk with Earnings and Penalty Caps $\ldots \ldots \ldots \ldots \ldots \ldots$

Current Applications of Earnings and Spending Caps ............. 37 
What Are the Risks Associated with DSM Shareholder Incentives? . . . . . . 38

Addressing Risk Aversion by Tailoring Incentive Designs . . . . . . . 40

Chapter 7: Aggregate Versus Separate Incentive Mechanisms $\ldots \ldots \ldots \ldots \ldots 43$

Separate Incentives for Individual DSM Resource Programs Will

Limit Efficiency . .........................43

When Is Separate Incentive Treatment of Individual DSM Programs

Appropriate? ...........................45

Equity Should Be Treated Carefully as a Separate Regulatory Objective .... 46

Chapter 8: Summary and Concluding Thoughts $\ldots \ldots \ldots \ldots \ldots \ldots \ldots$

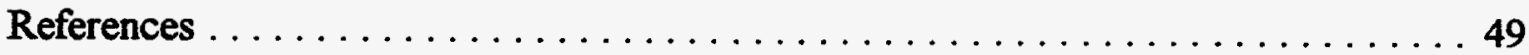

Appendix A: Descriptions of Ten Utility Incentive Programs $\ldots \ldots \ldots \ldots \ldots \ldots 3$

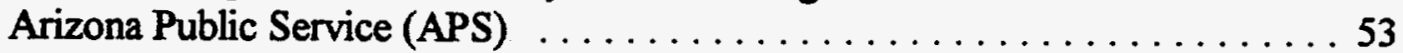

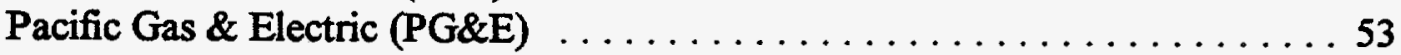

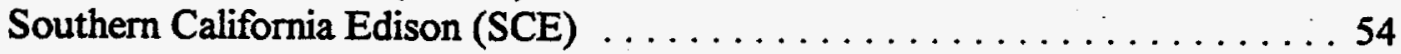

Midwest Power (Midwest) . . . . . . . . . . . . . . . . . . . 54

Massachusetts Electric Company (MECo) $\ldots \ldots \ldots \ldots \ldots \ldots \ldots \ldots \ldots 5$

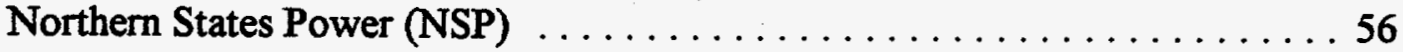

Jersey Central Power \& Light (ICP\&L) ................. 56

Consolidated Edison (Con Edison) . . . . . . . . . . . . . . . . . 57

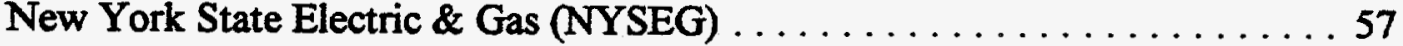

Portland General Electric (PGE) $\ldots \ldots \ldots \ldots \ldots \ldots \ldots \ldots \ldots \ldots \ldots$

Appendix B: What Is the Shape of the Hidden Cost Curve? . . . . . . . . . . 59

Appendix C: On the Operation of a 100\% Marginal Incentive Rate for

Shared Savings . . . . . . . . . . . . . . . . . . . 61

Appendix D: A Proposal for Sharing DSM Benefits $\ldots \ldots \ldots \ldots \ldots \ldots \ldots$ 


\section{Tables}

Table ES-1. Summary of 1992 DSM Expenditures and Shareholder Incentive

Earnings . . . . . . . . . . . . . . . . . . . . .

Table ES-2. Summary of DSM Shareholder Incentive Design Recommendations . . xix

Table 2-1. Utility DSM Shareholder Incentives - 1994 Program Year . . . . . . . . . . 4

Table 2-2. Summary of 1992 DSM Expenditures and Shareholder Incentive Earnings . 6

Table 3-1. Definitions of Net Benefits . . . . . . . . . . . . . . . 12

Table 4-1. 1993 and 1994 Forecasted Shared Savings Shareholder Incentives . . . . 20

Table 5-1. Classification of Shareholder Incentive Mechanisms . . . . . . . . . 28

Table 6-1. Earnings and Spending Caps for Eight Utility DSM Programs . . . . . . 38

Table 7-1. Treatment of Individual DSM Programs for Eight Utility DSM

Shareholder Incentives . . . . . . . . . . . . . . . . . . . . . . . 44

Table 8-1. Summary of Recommendations for the Design of DSM Shareholder

Incentives 


\section{Figures}

Figure ES-1. Structural Elements of a DSM Shareholder Incentive Mechanism . . . . xv

Figure 2-1. Structural Elements of a DSM Shareholder Incentive Mechanism ..... 7

Figure 5-1. Incentive Payments and Marginal Incentive Rates as a Function of

Net Benefits for Seven Shared Savings Mechanisms . . . . . . . . . . 26

Figure 5-2. Incentive Payments and Marginal Incentive Rates as a Function of

Percentage of Expected Net Benefits Achieved for Seven Shared Savings

Mechanisms . . . . ....................... 27

Figure 5-3. Performance Depends Upon the Marginal Incentive Rate as Well as the Hidden Cost Curve . . . . . . . . . . . . . . . . . . . . . . 29

Figure 5-4. Performance Level Depends Upon the Marginal Incentive Rate, Not Whether Hidden Costs Are Covered . . . . . . . . . . . . . . . 30

Figure 5-5. Edison's 1993 Incentive Payments and Marginal Incentive Rates as a Function of the Percentage of Expected Net Benefits Achieved . . . . . . 31

Figure 5-6. Edison's 1993 Incentive Payments and Marginal Incentive Rates as a Function of the Net Benefits Achieved $\ldots \ldots \ldots \ldots \ldots \ldots \ldots \ldots$

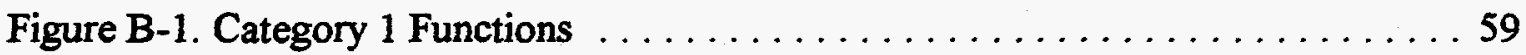

Figure B-2. A Category 2 Function $\ldots \ldots \ldots \ldots \ldots \ldots \ldots \ldots \ldots \ldots \ldots$

Figure B-3. Incentive Function Too Low Compared to Hidden Cost Function . . . 60

Figure C-1. Hidden Costs with Traditional (15\%) and Improved (50\%) Incentives . . 61

Figure C-2. Effect of a $100 \%$ Marginal Incentive Rate ............... 62

Figure C-3. The Effect of Errors in Estimated Hidden Cost. .............63 


\section{Acknowledgments}

We would like to express our appreciation to the following individuals for the information they contributed to our study:

\author{
Bill Barretti \\ New Jersey Board of \\ Regulatory Commissioners \\ Michael Cheng \\ Pacific Gas \& Electric

\section{Betsy Engelking \\ Minnesota Public Utilities \\ Commission}

Pamela Lai

Consolidated Edison of

New York

Jean Rokke

Northern States Power

Company

\author{
David Berry \\ Arizona Corporation \\ Commission \\ Michelle Cooke \\ California Public Utilities \\ Commission
}
Ann Hatcher
New England Power Service
Company

Scott Logan

California Public Utilities

Commission

Chris Siebens

Jersey Central Power \& Light

\author{
John Carney \\ Portland General Electric \\ Company
}

Gordon Dunn

Lowa Utilities Baard

Brian Hawley

New York State Electric \&

Gas

Ali Miremadi

California Public Utilities

Commission

Lee Sparling

Oregon Public Utilities

Commission

\section{Al Zeman}

Midwest Power

We also thank the following individuals for their comments on the draft of this report. However, the views and opinions expressed in this report are strictly those of the authors.

$\begin{array}{lll}\begin{array}{l}\text { Eric Hirst } \\ \text { Oak Ridge National } \\ \text { Laboratory }\end{array} & \begin{array}{l}\text { Theo MacGregor } \\ \text { Massachusetts Department } \\ \text { of Public Utilities }\end{array} & \begin{array}{l}\text { Peter Miller } \\ \text { Natural Resources Defense } \\ \text { Council }\end{array} \\ \begin{array}{l}\text { Jonathan Raab } \\ \text { Raab Associates }\end{array} & \begin{array}{l}\text { Don Schultz } \\ \text { California Public Utilities } \\ \text { Commission }\end{array} & \end{array}$

Finally, we thank our LBL colleagues, Chuck Goldman, Steve Wiel, and G. Alan Comnes for their comments on drafts of this report. 


\section{Acronyms and Abbreviations}

$\begin{array}{ll}\text { APS } & \text { Arizona Public Service } \\ \text { Con Edison } & \text { Consolidated Edison of New York } \\ \text { IRP } & \text { Integrated Resource Planning } \\ \text { JCP\&L } & \text { Jersey Central Power \& Light } \\ \text { MECo } & \text { Massachusetts Electric Company } \\ \text { Midwest } & \text { Midwest Power } \\ \text { NSP } & \text { Northern States Power } \\ \text { NYSEG } & \text { New York State Electric \& Gas } \\ \text { PG\&E } & \text { Pacific Gas \& Electric } \\ \text { PGE } & \text { Portland General Electric } \\ \text { RB } & \text { Ratebase } \\ \text { ROE } & \text { Return on Equity } \\ \text { SCE } & \text { Southern California Edison } \\ \text { TRC } & \text { Total Resource Cost } \\ \text { UC } & \text { Utility Cost }\end{array}$




\section{Executive Summary}

By the end of 1993, demand-side management (DSM) shareholder incentives had been approved for 53 electric and gas utilities in 20 states (Reid, Brown, and Deem 1993). ${ }^{1}$ With few exceptions, these incentives had been developed on a case-by-case basis. This report reviews recent DSM shareholder incentive designs and performance at 10 U.S. utilities. Through our review, we identify opportunities for regulators to improve the design of DSM shareholder incentive mechanisms to increase the procurement of cost-effective DSM resources. The lessons learned for DSM incentives are also applicable to other targeted forms of incentive regulation for the utility industry.

\section{Ten Utility DSM Shareholder Incentives}

Recent DSM program spending and incentive earnings for the 10 utilities are summarized in Table ES-1. DSM spending by the utilities ranged from $\$ 3.4$ million (APS) to $\$ 224.1$ million (PG\&E) in 1992 or, expressed as a percentage of total utility revenue, from 0.2 (APS) to 3.2 percent (MECo). The annual incentive payments received by the utilities ranged from $\$ 0.3$ million (APS) to $\$ 44.9$ million (PG\&E). Expressed as a percentage of net operating earnings, the range of payments was 0.03 (APS) to 6.2 percent (MECo). Direct comparison of these payments is appropriate because, in 1992, all of the utilities (except NSP) were separately assured of DSM program cost recovery and recovery of lost revenues.

We found three major classes of DSM shareholder incentives in our review: shared savings, which reward net benefits; bonuses, which reward energy and capacity savings; and markups, which reward spending. Several utilities (MECo and PGE) use hybrid incentives, which combine elements of these incentive types into a single formula. Two utilities (PG\&E and SCE) have separate mark-up and shared-savings incentive mechanisms, as well as separate spending targets for individual programs within their DSM portfolios.

1 An additional nine states had approved generic incentive mechanisms and four more were in the process of developing incentive mechanisms. 
Table ES-1. Summary of 1992 DSM Expenditures and Shareholder Incentive Earnings

\begin{tabular}{|c|c|c|c|c|c|c|}
\hline Utility & State & $\begin{array}{l}\text { Total DSM } \\
\text { Expenditures' } \\
\text { (Smillions) }\end{array}$ & $\begin{array}{c}\text { DSM } \\
\text { Expenditure/ } \\
\text { jlectric Operating } \\
\text { Revenue }^{2}\end{array}$ & $\begin{array}{c}\text { Shareholder } \\
\text { Incentives } \\
\text { Before Taxes' } \\
\text { (Smillions) }\end{array}$ & $\begin{array}{l}\text { Incentives/ } \\
\text { Total DSM } \\
\text { Expenditures }\end{array}$ & $\begin{array}{l}\text { Incentives/ } \\
\text { Net Operating } \\
\text { Income }\end{array}$ \\
\hline $\begin{array}{l}\text { Arizona Public Service } \\
\text { (APS) }\end{array}$ & $A Z$ & 3.4 & $0.2 \%$ & 0.3 & $8.8 \%$ & $0.03 \%$ \\
\hline $\begin{array}{l}\text { Pacific Gas \& Electric } \\
\text { (PG\&E) }\end{array}$ & $\mathrm{CA}$ & 224.1 & $2.9 \%$ & 44.9 & $20.0 \%$ & $1.7 \%$ \\
\hline $\begin{array}{l}\text { So. Calif. Edison } \\
\text { (SCE) }\end{array}$ & $\mathrm{CA}$ & 113.4 & $1.5 \%$ & 2.1 & $1.9 \%$ & $0.1 \%$ \\
\hline Midwest Power & IA & 19.1 & $3.1 \%$ & 1.5 & $7.6 \%$ & $0.8 \%$ \\
\hline $\begin{array}{l}\text { Mass. Elec. Co. } \\
\text { (MECo) }\end{array}$ & MA & 45.5 & $3.2 \%$ & 7.6 & $16.0 \%$ & $6.2 \%$ \\
\hline $\begin{array}{l}\text { Northem States Power } \\
\text { (NSP) }\end{array}$ & $\mathbf{M N}$ & 25.4 & $1.5 \%$ & 0.8 & $3.1 \%$ & $0.2 \%$ \\
\hline $\begin{array}{l}\text { Jersey Central Power \& } \\
\text { Light (JCP\&L) }\end{array}$ & NJ & 21.7 & $1.2 \%$ & 4.2 & $19.4 \%$ & $0.7 \%$ \\
\hline $\begin{array}{l}\text { Consolidated Edison } \\
\text { (Con Edison) }\end{array}$ & $\mathrm{NY}$ & 117.0 & $2.4 \%$ & 28.8 & $24.6 \%$ & $1.1 \%$ \\
\hline $\begin{array}{l}\text { NY State Electr. \& Gas } \\
\text { (NYSEG) }\end{array}$ & $\mathrm{NY}$ & 40.6 & $2.8 \%$ & 16.1 & $39.7 \%$ & $2.6 \%$ \\
\hline $\begin{array}{l}\text { Portland General Elec. } \\
\text { (PGE) }\end{array}$ & OR & 10.7 & $1.2 \%$ & 10.1 & $94.3 \%$ & $3.0 \%$ \\
\hline
\end{tabular}

1 Total DSM expenditures include the utilities' entire DSM program expenditures, including evaluation costs, as well as expenditures on load management and load retention programs and programs for which the utility receives no incentive.

2 Electric utility operating revenue was obtained from the annual financial filings of the utility with the Federal Energy Regulatory Commission (FERC), as reported by the Energy Information Administration (EIA 1993).

3 Shareholder incentives represent before tox incentive payments to the utility. The incentive payments for APS and PGE include the net present value of the expected incentive payment stream. The incentive payment to Midwest applies to the 1990 - 1992 period and reflects the Commission's recent downward adjustment. The incentive payments and expenditures for JCP\&L apply to the 1993 program year because JCP\&L had little DSM activity in 1992. The incentive payment for PG\&E has been adjusted to reflect adjustments made by the California Public Utilities Commission that are applicable to the 1992 program year.

4 Net Operating Income was obtained from EIA (1993) and was calculated by adding back in all tax items to the net electric utility operating income. 
Figure ES-1. Structural Elements of a DSM Shareholder Incentive Mechanism

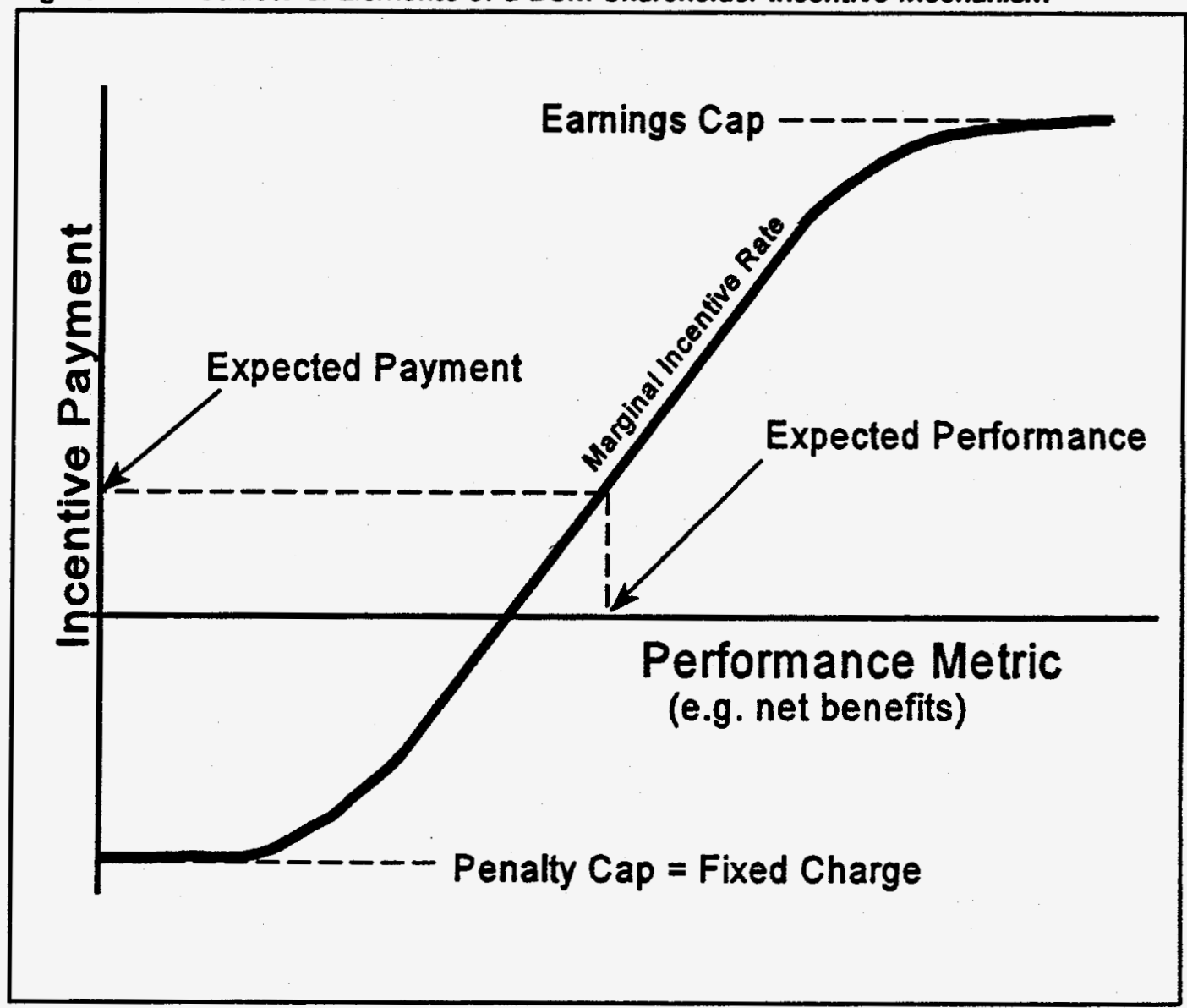

We use our review to discuss five design issues for DSM shareholder incentives: (1) the appropriate quantity to reward, e.g., net benefits, saved energy, or monies spent (the quantity on the horizontal axis in Figure ES-1); (2) considerations for establishing the expected incentive payment (the point on the vertical axis associated with a given level of performance); (3) the importance of and optimal value for the marginal incentive rate (the slope of the incentive payment curve); (4) the role of earnings and penalty caps to mitigate risks to both the utility and the regulator (the tapering off of the incentive payment curve at very high and low levels of performance); and (5) the justifications for aggregate versus separate incentive mechanisms (not shown on the Figure).

\section{Evaluating Overall Designs for DSM Shareholder Incentives}

We advocate the use of shared-savings incentive mechanisms because they can directly ensure consistency between the maximization of net benefits to society and the financial interests of the utility. However, the ability of a shared-savings incentive to meet this objective can be 
compromised both by inaccurate specification of net benefits (for example, specifying net benefits using just utility costs (UC), rather than the total resource costs (TRC)) and also by the common practice of placing spending or earnings caps on individual utility DSM programs. We observe that bonuses require the use of a separate TRC test to ensure cost effectiveness, which makes their regulation burdensome compared to shared savings. Markups are susceptible to abuse by utilities, but sometimes can be justified when net benefits are difficult to measure.

Hybrid incentives must be designed carefully to ensure that the resulting weighting of individual incentives accurately reflects regulatory preferences. In cases where energy savings are rewarded in addition to net benefits, we remain concerned that use of the bonus incentive approach is generally inappropriate. In cases where minimizing rate impacts is combined with maximizing net benefits (e.g., by combining utility and total resource costs in the net benefit calculation), careful consideration should be given to the relative importance of these two objectives.

\section{Principles for Establishing Incentive Payments}

As indicated in Table ES-1, DSM shareholder incentive payments vary considerably, even after normalizing for differences in utility size. Our analysis draws from the economic literature on incentive regulation to identify important considerations for establishing these payments. We defend the conventional economist's view that utilities incur hidden costs when they pursue DSM and that, therefore, a fair incentive must mitigate these costs. We then describe the components of these costs. They consist of the very real, but unobservable, management costs associated with the additional effort and organizational changes required to implement successful DSM programs, as well as the opportunity costs associated with potentially under-recovered DSM program costs or net lost revenues and utility activities foregone because of the pursuit of DSM programs. Management costs may be relatively larger in the early phases of DSM program implementation, while opportunity costs will be larger in later phases. Estimating these costs is difficult although an approach for estimating opportunity costs is well-defined conceptually. The biggest challenge to estimating opportunity costs is accounting for the relative riskiness of various foregone opportunities; for example, DSM programs with guaranteed cost recovery may be considered less risky than shareholder-financed supply projects.

\section{The Importance of Marginal Incentive Rates}

A major contribution of our report is the distinction we make between incentive design issues related to the expected incentive payment and those related to the marginal incentive payment. When regulators use shared savings, we advocate higher marginal incentive rates than are currently observed in practice as an effective means of motivating utilities to secure all cost-effective DSM. We argue that an optimal incentive would be provided by paying a 
$100 \%$ marginal incentive rate to shareholders around some expected range of performance. Such a marginal incentive would drive the utility toward the acquisition of all cost-effective DSM.

Offering high marginal incentive rates, however, need not lead to large incentive payments. A utility could be paid any desired amount on average through the introduction of a fixed charge. Decoupling marginal incentive rates from the expected incentive payments in this fashion allows regulators to set each separately in order to send the desired regulatory signal. (As indicated earlier, we believe expected payments should compensate a utility for its hidden costs.)

\section{Mitigating Risks with Earnings, Spending, and Penalty Caps}

It is easy to limit the regulator's up-side risk with an earnings cap, and to limit the utility's down-side risk with a penalty cap. The magnitude of these risks increases with higher marginal incentive rates. Regulators should recognize, however, that a penalty cap can impose some risk on the regulator that the utility will discontinue all DSM activities if it expects to fall within the penalty region. This problem can be reduced by using a very moderately sloped incentive region in place of a strict penalty cap.

More importantly, an earnings cap removes incentives for extraordinary performance. When a shared savings incentive is used, we question the wisdom of reducing the marginal incentive rate for performance that is significantly above expectations, although we acknowledge that there are regulatory risks associated with under-forecasting utility performance. Nevertheless, as long as the marginal incentive rate is no more than 100 percent (see above), regulators should carefully compare these risks to the benefits associated with acquiring additional net socially beneficial DSM, regardless of the program target.

\section{Aggregate Versus Separate Incentive Mechanisms}

Our review of current DSM shareholder incentive mechanisms reveals a variety of design features that limit the effectiveness of DSM incentive mechanisms. These include separate spending targets, performance thresholds, and incentive formulas for individual DSM program elements. Ensuring equity is often mentioned as a justification for these approaches.

Generally speaking, we believe rigid spending limits and separate incentive treatments for individual DSM resource programs are inappropriate because they undermine the desirable incentive properties of shared-savings incentive mechanisms. That is, with few exceptions, these constraints prevent the utility from allocating DSM budget resources to the most costeffective DSM resource opportunities. We believe, in particular, that equity can and should be treated as a separate regulatory goal in ways that do not compromise this desirable incentive property of the shared-saving incentive mechanism. 
The primary exception is programs whose benefits are difficult to measure, but are known to be positive, such as information programs. For these programs, the use of a markup is the only practical incentive. Customer service programs whose objectives are clearly not the maximization of net resource benefits also fit in this category. But it makes no sense to use a DSM shareholder incentive mechanism intended to motivate a utility to maximize net social benefit to also motivate superior provision of service-oriented, non-resource DSM programs, such as programs for low-income customers. Finally, under very restrictive conditions, separate incentives can also be appropriate for DSM resources that may become "lost opportunities."

\section{Summary of DSM Shareholder Incentive Design Recommendations}

Examination of utility DSM shareholder incentives provides regulators with a unique opportunity to evaluate the effectiveness of a particular type of targeted incentive regulation. We observe that current mechanisms can probably be improved by harnessing their incentive powers more deliberately to ensure better alignment of regulatory objectives and utility financial self-interests. Better alignment reduces adversarial confrontation and eliminates the need for regulatory micro-management. Table ES-2 summarizes our recommendations to improve the design of DSM shareholder incentives.

As regulators contemplate other applications of incentive regulation, the lessons from DSM shareholder incentives are clear. Be explicit about the regulatory objective; then, when considering multiple objectives, look broadly at alternatives that have the potential to meet these objectives without compromising the incentive properties of the mechanisms. 
Table ES-2. Summary of DSM Shareholder Incentive Design Recommendations

\begin{tabular}{|l|l|}
\hline Shareholder Incentive Design Issue & LBL Recommendation \\
\hline DSM Resource Programs & $\begin{array}{l}\text { Apply shared-savings incentives to DSM } \\
\text { resource programs }\end{array}$ \\
\hline DSM Information Programs & $\begin{array}{l}\text { Use separate incentives for individual } \\
\text { programs only when net benefits are difficult } \\
\text { to measure, but are known to be positive }\end{array}$ \\
\hline Expected Incentive Payment & $\begin{array}{l}\text { Set expected incentive payments based on } \\
\text { covering a utility's "hidden costs, which } \\
\text { include some transitional management and } \\
\text { risk-adjusted, opportunity costs }\end{array}$ \\
\hline Marginal Incentive Rate & $\begin{array}{l}\text { Use higher marginal incentive rates than are } \\
\text { currently found in practice, but limit total } \\
\text { incentive payments by adding a fixed charge }\end{array}$ \\
\hline Regulatory Risk Mitigation & $\begin{array}{l}\text { Mitigate regulator's over-payment risks from } \\
\text { under-forecasting by lowering the marginal } \\
\text { incentive rate for high performance levels }\end{array}$ \\
\hline Utility Risk Mitigation & $\begin{array}{l}\text { Mitigate earnings risks to utilities by lowering } \\
\text { the marginal incentive rate for low } \\
\text { performance levels }\end{array}$ \\
\hline $\begin{array}{l}\text { Aggregate vs. Separate Incentive } \\
\text { Programs }\end{array}$ & $\begin{array}{l}\text { Use an aggregate incentive mechanism for all } \\
\text { DSM resource programs, with limited } \\
\text { exceptions }\end{array}$ \\
\hline
\end{tabular}




\section{Introduction}

By the end of 1993, demand-side management (DSM) shareholder incentives had been approved for 53 electric and gas utilities in 20 states (Reid, Brown, and Deem 1993). Since then an additional nine states have approved generic incentive mechanisms and four more are in the process of developing incentive mechanisms. With few exceptions, the incentives have been developed case by case. This report reviews recent DSM shareholder incentive designs and performance at $10 \mathrm{U}$.S. utilities. Through our review, we identify opportunities for regulators to improve the design of DSM shareholder incentive mechanisms to increase the procurement of net beneficial DSM. The lessons learned for improving DSM shareholder incentive designs are applicable to other targeted forms of incentive regulation for the utility industry.

Our examination of DSM shareholder incentives is based on two major assumptions; we start with the assumption that the overriding regulatory objective is the maximization of social value or societal net benefits, which is consistent with the rationale for integrated resource planning (IRP) (Krause and Eto 1988). This assumption is critical to our review because we believe that the efficacy of incentives can only be analyzed with explicit reference to particular regulatory objectives. In several instances, we identify interactions between maximization of societal benefits and other regulatory objectives. Our purpose is not to question the legitimacy of any objective, but to indicate where they may involve tradeoffs, and where they are complementary.

Our second major assumption is that disincentives or hidden costs are associated with utility pursuit of DSM net benefits, and that these costs must be overcome by a fair shareholder incentive (Nadel, Reid, and Wolcott 1992). This now conventional perspective does not mean that DSM shareholder incentives are the only way to overcome these disincentives, but it does mean that the success of DSM shareholder incentives as a regulatory strategy depends on how well disincentives or hidden costs are addressed. We discuss the ways that incentives should change as utilities become familiar with acquiring DSM resources.

This report has seven chapters following this introduction. In Chapter 2, we summarize 10 recent DSM shareholder incentives, reviewing both basic design features and recent performance. In Chapter 3, we discuss the rationale for alternative incentive designs, focusing on the superiority of the shared-savings incentive for achieving the regulatory objective of maximizing net benefits. In Chapter 4, we analyze the hidden cost and incentive regulation principles associated with setting expected incentive payments. In Chapter 5 , we examine the often overlooked role of the marginal incentive rate, which can be a powerful tool for communicating regulatory priorities and which can be decoupled from the expected incentive payment. In Chapter 6, we describe the role of earnings and penalty caps for mitigating risks to the regulator and utility, respectively. In Chapter 7, we look at the rationales for 
aggregate versus separate incentive mechanisms. Chapter 8 summarizes our conclusions. Appendix A contains more detailed descriptions of the 10 utility shareholder incentive programs we use. Appendix B discusses alternative specifications for the assumed shape of the hidden cost curve used in our analysis in Chapter 5. Appendix $\mathrm{C}$ provides additional discussion on the use of an optimal marginal incentive rate for shared-savings incentives. Finally, Appendix D discusses a new approach for ensuring equitable distribution of DSM net benefits. 


\section{Ten Utility DSM Shareholder Incentives}

We have selected a small sample of DSM shareholder incentives to introduce the current incentive designs and practices that will be the focus of detailed examination in subsequent chapters. We first review the basic design of the incentives and the associated ratemaking treatment of net lost revenues. We then summarize recent performance of the incentives, typically drawing from the 1992 program year. Finally, we abstract from the individual incentives to propose a typology of generic DSM shareholder incentive design issues, which we then address individually in each of the next five chapters of the report.

\subsection{Recent DSM Shareholder Incentive Designs}

To ground our discussion of design issues, we examined 10 recent DSM shareholder incentive mechanisms. The selection process was ultimately subjective, intended primarily to illustrate the diversity in current practice, but guided by several qualitative considerations. First, we selected mechanism designs that are currently in place. Second, we selected a diversity of incentive mechanism designs. Third, we considered the size of the incentive payments (four of the incentives resulted in payments in excess of $\$ 10$ million in 1992) and geographic diversity (four of the utilities are on the east coast, four on the west coast, and two from the central part of the U.S.).

Table 2-1 summarizes basic design features of 10 utility DSM shareholder incentives for the 1994 program year. ${ }^{2}$ The designs fall into three basic categories: bonus, savings, and markup incentive mechanisms. ${ }^{3}$ Bonus mechanisms reward utility shareholders on a per-unit basis for energy and demand savings. For example, APS provides a reward of about $\$ 104$ per kilowatt $(\mathrm{kW})$ saved. Bonus mechanisms, which are somewhat less common than shared savings mechanisms, have been adopted by utilities in six states (Reed, Brown, and Deem 1993).

The shared-savings incentive mechanism provides utility shareholders with a share of the energy savings benefits or "net benefits." For example, Con Edison provides shareholders with 23 percent (before tax) of the net benefits achieved for its 1993 and 1994 DSM programs. Shared-savings incentive mechanisms are the most common and have been adopted by utilities in 16 states.

Finally, markup mechanisms provide a markup on DSM program expenditures, generally varying from 5 to 10 percent. Markup mechanisms frequently apply to a subset of utility

More detailed descriptions of the incentive mechanisms are provided in Appendix A.

3

Some utilities have also adopted so-called return on equity (ROE) adjustment mechanisms and ratebase (RB) bonus mechanisms, but, as we will show in Chapter 3, these generally fall into one of the three categories we have identified. 
programs where energy savings benefits are particularly difficult to measure (e.g., information programs) or where the programs are undertaken based on equity rather than efficiency considerations (e.g., low-income housing). For example, PG\&E of California receives a five percent markup on its information and audit programs, but also receives shared-savings incentives for its "resource-based" DSM programs.

Table 2-1. Utility DSM Shareholder Incentives - 1994 Program Year

\begin{tabular}{|l|l|l|c|}
\hline \multicolumn{1}{|c|}{ Utility } & State & \multicolumn{1}{|c|}{$\begin{array}{c}\text { DSM Shareholder } \\
\text { Incentive Mechanism(s) }\end{array}$} & $\begin{array}{c}\text { Lost Revenue } \\
\text { Recovery } \\
\text { Mechanism }\end{array}$ \\
\hline Arizona Public Service (APS) & AZ & Bonus & Yes \\
\hline Pacific Gas \& Electric (PG\&E) & CA & Shared Savings \& Markup & Decoupling \\
\hline Southern California Edison (SCE) & CA & Shared Savings \& Markup & Decoupling \\
\hline Midwest Power (Midwest) & IA & Shared Savings & Yes \\
\hline Massachusetts Electric Company (MECo) & MA & $\begin{array}{l}\text { Shared Savings' } \\
\text { Bonus Hybrid }\end{array}$ & Decouplingt \\
\hline Northern States Power (NSP) & MN & Bonus & Partial \\
\hline Jersey Central Power \& Light (JCP\&L) & NJ & Shared Savings & Yes \\
\hline Consolidated Edison (Con Edison) & NY & Shared Savings & Yes \\
\hline New York State Electric \& Gas (NYSEG) & NY & Shared Savings & Yes \\
\hline Portland General Electric (PGE) & OR & $\begin{array}{l}\text { Shared Savings' } \\
\text { Bonus Hybrid }\end{array}$ & Yes \\
\hline
\end{tabular}

$\dagger$ Although the Massachusetts Department of Public Utilities provides no treatment of lost revenues for MECo, MECo through its generating affiliate, New England Power System, is made whole for lost revenues through rate cases at FERC, which has the same effect as decoupling (see Eto, Destribats, and Schultz 1992).

Two utilities (MECo and PGE) use hybrid incentives, which combine elements of several of these incentive types into a single formula: MECo's hybrid incentive combines a bonus with a shared-savings incentive mechanism. PGE's hybrid incentive combines a bonus and two forms of shared savings, one of which provides an incentive to minimize rate impacts. See Appendix A for additional details on these and the incentive mechanisms of the other eight utilities. 
Table 2-1 also summarizes the lost revenue recovery mechanisms used by regulators for each utility. ${ }^{4}$ Gallagher (1991) has shown that accounting for the existence of these mechanisms is critical for understanding the net effect of a DSM shareholder incentive. For the most part, the DSM shareholder incentives we examine address lost revenues either through lost revenue or decoupling mechanisms. This allows us to compare DSM incentive payments across utilities without specific attention to otherwise offsetting influences arising from underrecovery of program costs or lost revenues.

\subsection{DSM Spending and Shareholder Incentive Earnings}

Table 2-2 compares DSM spending and DSM shareholder incentives for the most recent year for which comparable information is available for each utility, 1992. DSM spending by the utilities ranged from $\$ 3.4$ (APS) to $\$ 224.1$ million (PG\&E) in 1992. Expressed as a percentage of total utility revenue, the range is from 0.2 percent (APS) to 3.2 percent (MECo). This range is consistent with the current range of U.S. utility spending on DSM, which is to say that few utilities are spending more than 3 percent on DSM although many, generally smaller utilities are spending less than 0.2 percent.

The incentive payments received by the utilities in 1992 range from $\$ 0.3$ (APS) to $\$ 44.9$ million (PG\&E). Expressed as a percentage of net operating income, the range of payments is 0.03 percent (APS) to 6.2 percent (MECo). The range is weighted more heavily toward the smaller values. ${ }^{6}$

While the DSM shareholder incentive designs fall generally into the three categories discussed above, individual incentives differ greatly (see Table $2-1$ ). The marginal incentive rate for APS's bonus incentive is $\$ 104 / \mathrm{kW}$, whereas MECo's is $\$ 1.53 / \mathrm{kW}$ and $0.11 \% / \mathrm{kWh}$ for savings above the 50 percent threshold. The marginal incentive rates for the markup incentives vary from 2 to 12 percent, and the marginal incentive rates for the shared savings incentives display even greater variability, ranging from 1 percent to infinity. Most DSM shareholder incentives feature earnings or spending caps.

4 See Eto, Stoft, and Belden (1994) for a detailed examination of the lost revenue issue and a description of decoupling mechanisms to address it.

5 Concern remains regarding the lack of symmetry in the incentive properties of net lost revenue adjustments (see, for example, Moskovitz, Harrington, and Austin 1992); in this report we do not question their ability to remove the disincentives associated with lost sales resulting from successful conservation programs.

6 See also Nadel and Jordan (1992) for additional approaches to examining the relationship between shareholder incentives and various measures of DSM program size. 
Table 2-2. Summary of 1992 DSM Expenditures and Shareholder Incentive Earnings

\begin{tabular}{|c|c|c|c|c|c|c|}
\hline Utility & State & $\begin{array}{l}\text { Total DSM } \\
\text { Expenditures } \\
\text { (Smillions) }\end{array}$ & $\begin{array}{c}\text { DSM } \\
\text { Expenditure/ } \\
\text { Electric Operating } \\
\text { Revenue }^{2}\end{array}$ & $\begin{array}{l}\text { Shareholder } \\
\text { Incentives } \\
\text { Before Taxes } \\
\text { (Smillions) }\end{array}$ & $\begin{array}{c}\text { Incentives/ } \\
\text { Total DSM } \\
\text { Expenditures }\end{array}$ & $\begin{array}{l}\text { Incentives } \\
\text { Net Operating } \\
\text { Income }\end{array}$ \\
\hline $\begin{array}{l}\text { Arizona Public Service } \\
\text { (APS) }\end{array}$ & $\mathbf{A Z}$ & 3.4 & $0.2 \%$ & 0.3 & $8.8 \%$ & $0.03 \%$ \\
\hline $\begin{array}{l}\text { Pacific Gas \& Electric } \\
\text { (PG\&E) }\end{array}$ & $\mathrm{CA}$ & 224.1 & $2.9 \%$ & 44.9 & $20.0 \%$ & $1.7 \%$ \\
\hline $\begin{array}{l}\text { So. Calif. Edison } \\
\text { (SCE) }\end{array}$ & $\mathrm{CA}$ & 113.4 & $1.5 \%$ & 2.1 & $1.9 \%$ & $0.1 \%$ \\
\hline Midwest Power & IA & 19.1 & $3.1 \%$ & 1.5 & $7.6 \%$ & $0.8 \%$ \\
\hline $\begin{array}{l}\text { Mass. Elec. Co. } \\
\text { (MECo) }\end{array}$ & MA & 45.5 & $3.2 \%$ & 7.6 & $16.0 \%$ & $6.2 \%$ \\
\hline $\begin{array}{l}\text { Northem States Power } \\
\text { (NSP) }\end{array}$ & $\mathbf{M N}$ & 25.4 & $1.5 \%$ & 0.8 & $3.1 \%$ & $0.2 \%$ \\
\hline $\begin{array}{l}\text { Jersey Central Power \& } \\
\text { Light (JCP\&L) }\end{array}$ & NJ & 21.7 & $1.2 \%$ & 4.2 & $19.4 \%$ & $0.7 \%$ \\
\hline $\begin{array}{l}\text { Consolidated Edison } \\
\text { (Con Edison) }\end{array}$ & $\mathrm{NY}$ & 117.0 & $2.4 \%$ & 28.8 & $24.6 \%$ & $1.1 \%$ \\
\hline $\begin{array}{l}\text { NY State Electr. \& Gas } \\
\text { (NYSEG) }\end{array}$ & $N Y$ & 40.6 & $2.8 \%$ & 16.1 & $39.7 \%$ & $2.6 \%$ \\
\hline $\begin{array}{l}\text { Portland General Elec. } \\
\text { (PGE) }\end{array}$ & OR & 10.7 & $1.2 \%$ & 10.1 & $94.3 \%$ & $3.0 \%$ \\
\hline
\end{tabular}

1 Total DSM expenditures include the utilities' entire DSM program expenditures, including evaluation costs, as well as expenditures on load management and load retention programs and programs for which the utility receives no incentive.

2 Electric utility operating revenue was obtained from the annual financial filings of the utility with the Federal Energy Regulatory Commission (FERC), as reported by the Energy Information Administration (ELA 1993).

3 Shareholder incentives represent before tox incentive payments to the utility. The incentive payments for APS and PGE include the net present value of the expected incentive payment stream. The incentive payment to Midwest applies to the 1990-1992 period and reflects the Commission's recent downward adjustment. The incentive payments and expenditures for JCP\&L apply to the 1993 program year because JCP\&L had little DSM activity in 1992. The incentive payment for PG\&E has been adjusted to reflect adjustments made by the California Public Utilities Commission that are applicable to the 1992 program year.

4 Net Operating Income was obtained from EIA (1993) and was calculated by adding back in all tax items to the net electric utility operating income.

In many cases, incentives are calculated for a utility's entire DSM portfolio; in other cases, separate incentives apply to individual DSM programs. For example, APS's incentive mechanism only applies to two of its pilot programs but not to its information programs. In California, a markup is applied to audit and information programs, and a shared-savings incentive is applied to "resource-based" programs where the net benefits are more easily 
measured. In addition, California utilities also have a large category that includes DSM pilot programs and DSM measurement and evaluation activities that are not eligible for incentives. Finally, JCP\&L receives incentives on its "performance-based" programs, but not for its "core" programs.

A final difference among these programs is whether incentive payments are made ex ante based on engineering estimates, or ex post based upon evaluation approaches that introduce measured information from actual installations. In the past, utilities have relied on ex ante estimates, but, for a variety of reasons, public utility commissions are increasingly calling for ex post measurement and evaluation. We do not address this issue in this report, referring the reader instead to recent work by Violette and Raab (1994), and Schlegel et al. (1993).

\subsection{A Typology of DSM Shareholder Incentive Design Elements}

Figure 2-1 summarizes the generic design features of DSM shareholder incentive mechanisms. The first issue, which is reflected in the basic design of the incentive mechanisms, is the performance being rewarded (see Chapter 3). In Figure 2-1, this is the quantity on the

Figure 2-1. Structural Elements of a DSM Shareholder Incentive Mechanism

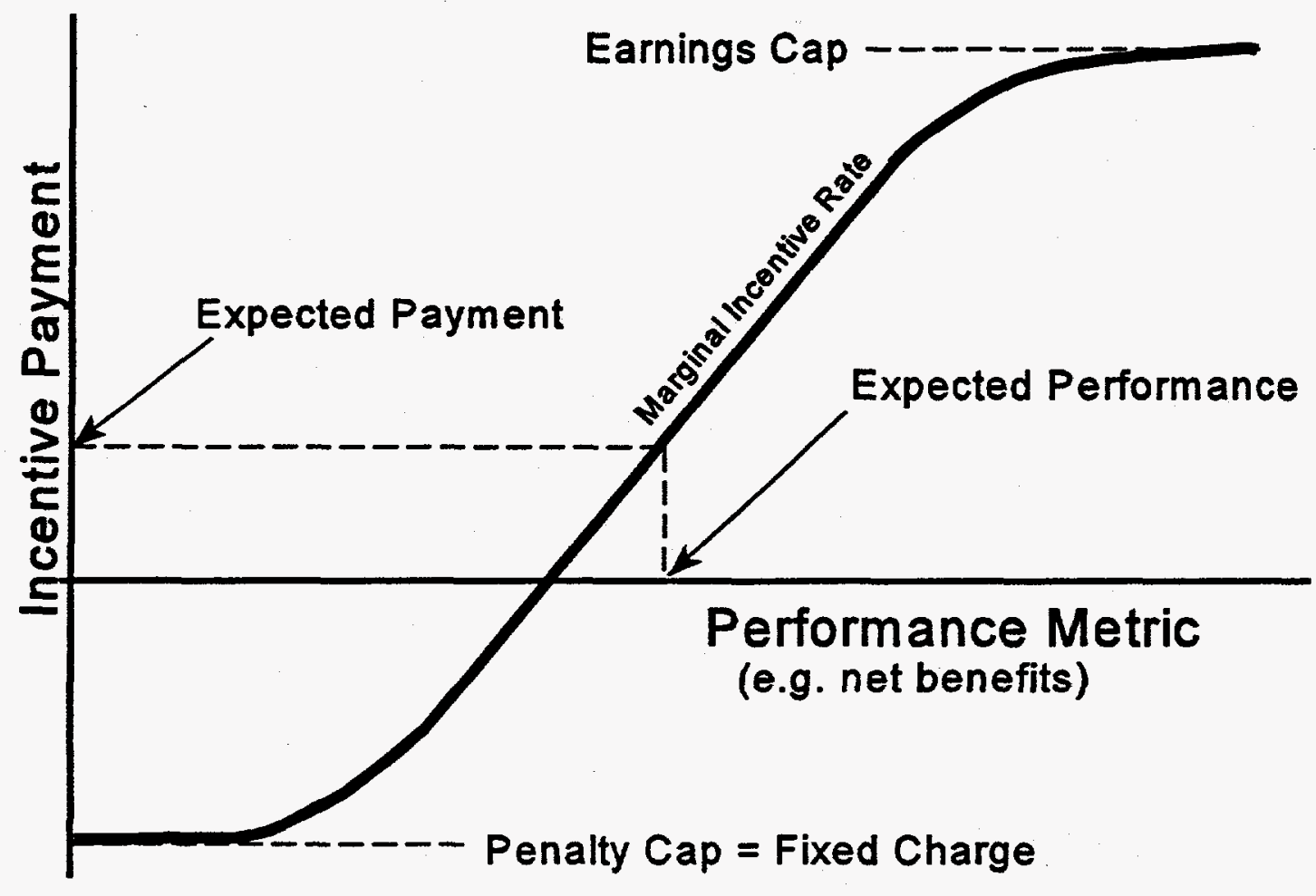


horizontal axis. The second issue is the size of the incentive payment for a given level of performance (see Chapter 4). This is a point on the vertical axis associated with a given level of performance. The third issue is the marginal incentive rate or the slope of the incentive payment curve as a function of changes in performance (see Chapter 5). The fourth issue is the use of earnings and penalty caps, which we represent as a flattening of the incentive payment curve at high and low levels of performance (see Chapter 6). A fifth design element, not reflected in Figure 2-1, is whether to use aggregate or separate incentives for individual DSM programs (see Chapter 7). 


\section{Evaluating Overall Designs for DSM Shareholder Incentives}

This chapter reviews the basic design of current DSM shareholder incentives. We first present a classification scheme for DSM incentives. We then analyze the three basic incentive designs from the perspective of their ability to motivate a utility to maximize DSM net benefits. We describe: (1) the additional conditions required to ensure that bonuses are cost effective; (2) the potential pitfalls associated with the theoretically superior shared-savings incentive mechanism; and (3) the limited situations in which markups are appropriate. We also discuss hybrid incentives, which combine one or more of these basic designs, to introduce some of the complexities associated with providing incentives to achieve more than one regulatory objective. Using incentives to achieve multiple regulatory objectives through separate incentive treatment of individual DSM programs is also taken up briefly in Chapter 7.

\subsection{A Classification Scheme for DSM Shareholder Incentive Designs}

DSM incentive mechanisms fall into three categories: bonus, shared savings, and markup. Bonus mechanisms provide a per-unit reward for energy and demand savings. Shared savings mechanisms give utilities a share of the energy savings benefits, or "net benefits" from DSM. Net benefits are generically defined as the avoided benefits less the program costs. Markup mechanisms provide markups on DSM program expenditures. We define these relationships formally, using the following equations (Stoft and Gilbert 1994) ${ }^{7}$ :

$\begin{array}{llll}\text { Bonus: } & \mathrm{I} & =\lambda \mathrm{Q}-\mathrm{F} \\ \text { Shared Savings: } & \mathrm{I} & =\lambda\left(\mathrm{AQ}-\mathrm{C}_{\mathrm{u}}-\mathrm{C}_{\mathrm{p}}\right)-\mathrm{F} \\ \text { Markup: } & \mathrm{I} & =\lambda \mathrm{C}_{\mathrm{u}}-\mathrm{F}\end{array}$

7 In addition to these incentive designs, some utilities have adopted return on equity (ROE) adjustment mechanisms and ratebase (RB) bonus mechanisms. We believe these incentives fall into the three categories discussed above. RB bonus mechanisms adjust the allowed rate of return on ratebased DSM program expenditures and ROE adjustments work in a similar fashion, allowing increases in a utility's ROE. These two mechanisms fall into the "bonus/unit" category when the bonus depends upon the amount of energy saved and into the markup and shared savings categories when the incentive payment depends upon expenditures or net benefits, respectively. 
where,

$\begin{array}{lll}\mathbf{I} & = & \text { incentive payment; } \\ \lambda & = & \text { incentive rate; } \\ \mathrm{A} & = & \text { per-unit avoided energy and capacity costs; } \\ \mathbf{Q} & = & \text { quantity of energy saved; } \\ \mathbf{C}_{\mathbf{u}} & = & \text { utility program costs; } \\ \mathbf{C}_{\mathbf{p}} & = & \text { participant costs; and } \\ \mathbf{F} & = & \text { fixed payment. }\end{array}$

The fixed payment term, which sets the magnitude of the incentive payment at an expected level or performance and may result in penalties if the utility fails to undertake a DSM program, merits some explanation. For example, if a utility had a bonus incentive mechanism with $\lambda$ equal to $1 \notin$ per kilowatt hour and $\mathrm{F}$ equal to $\$ 1$ million (i.e., $\mathrm{I}=1 \notin / \mathrm{kWh} * \mathrm{Q}-\$ 1$ million), then the utility would incur penalties of $\$ 1$ million if no energy is saved. On the other hand, the utility would break even if it saved 100 million $\mathrm{kWh}$ and would earn $\$ 1$ million if it saved 200 million $\mathrm{kWh}$. In our survey, we only found shared savings mechanisms with fixed payment terms, but, in principle, they could also be used in conjunction with both the bonus and markup mechanisms. ${ }^{8}$

\subsection{Use of Bonus Mechanisms Requires TRC Constraints to Ensure IRP Objectives Are Met}

From an integrated resource planning (IRP) perspective, the purpose of an incentive mechanism should be to maximize the net benefits from the DSM program, not just energy or capacity savings. To illustrate this point and its importance for the design of incentives, consider the possible results of a hypothetical bonus mechanism that rewards energy savings. ${ }^{9}$ Typically, as with most incentive programs, the DSM program has an expenditure cap. For this example, assume that the bonus is $1 \notin / \mathrm{kWh}$ and that the cost of supply is $8 \% / \mathrm{kWh}$. Also assume that the DSM expenditure cap is high enough and that inducing energy savings is difficult enough that, after spending all but the last $\$ 1$ million of its budget the utility has been reduced to installing quite inefficient DSM measures, which cost the utility $20 \mathrm{k} / \mathrm{kWh}$. What will the utility do? Because most commissions reimburse utilities for program costs, the utility knows that for each $20 \notin$ it spends, it will receive a $20 \notin$ reimbursement plus a $1 \notin$ reward for the saved $\mathrm{kWh}$. Thus, even though the DSM program is wasting $12 \phi / \mathrm{kWh}(20 \phi-8 \phi)$,

8 In Chapter 4, we discuss how these fixed payments can break the link between the marginal incentive rate and the expected incentive payment.

9 This example is an exaggeration to illustrate the potential problems associated with bonus mechanisms. It ignores the participant's perspective, which would affect the ability of the utility to market such a program. 
the utility will spend its last $\$ 1$ million on these inefficient measures in order to eam the $\$ 50,000$ reward. The net result is $\$ 600,000$ of waste imposed on ratepayers followed by a $\$ 50,000$ transfer payment from ratepayers to utility stockholders as a reward.

In fairness, many bonus mechanisms require that the individual programs or measures pass a TRC test before they are implemented. ${ }^{10}$ This requirement helps to avoid the situations such as the one described in our example, but it does not prevent them entirely. This is because a program with a marginal cost of $20 \mathrm{c} / \mathrm{kWh}$ may still pass a TRC test, since this a test is based on averages. Thus, while the average cost of conserved energy for a program may be low, the cost for the marginal DSM measure may be quite high. As we will discuss, a utility would have an incentive to avoid these marginal measures with a shared savings program, but not with a bonus program.

TRC tests could take into account marginal net benefits, and public utility commissions could require that programs under a bonus mechanism each be carried out to the point where the marginal net benefits were equal across programs. But this just turns a bonus mechanism into a shared savings mechanism. The advantage of the bonus is that it is simple, but by forcing a careful computation of the TRC test one has reintroduced all of the complexity that bonus mechanisms were meant to avoid.

However, bonus mechanisms do not perform poorly when the utility has plenty of "cheap" DSM measures (i.e., measures that cost less than the avoided cost benefits). In these instances, the bonus mechanisms motivate suboptimal behavior, but they do not necessarily induce behavior that is detrimental to the public good. They simply cause the utility to maximize benefits minus utility cost, instead of total benefits minus social cost. ${ }^{11}$ This will tend to bias the utility towards programs with low utility costs. Of course, these programs may well also have high participant costs and, thus, high social costs. It is these participant costs that bonus mechanisms fail to induce the utility to avoid. Thus, with a bonus mechanism and plenty of "cheap" DSM measures, the utility would not generate negative net benefits (from a utility cost perspective), but it would have no incentive to generate the greatest positive social benefits.

The TRC test is defined as the avoided cost benefits less the utility program costs and incremental participant costs. probably optimizing $\mathrm{kWh}$ per utility dollar spent rather than benefit per utility dollar spent. 


\subsection{Shared-Savings Incentive Mechanisms Provide Superior IRP Incentives, When Properly Defined}

We advocate the use of shared-savings incentive mechanisms because they can directly ensure consistency between the regulatory objective of maximizing net social benefits and the financial interests of the utility (Eto, Destribats, and Schultz 1992). We observe, however, that this consistency is not achieved automatically. The regulatory objective can be compromised both by incomplete specification of net benefits (for example, specifying net benefits using the utility costs, rather than the total resource costs) and also by the common practice of placing spending or earnings caps on individual utility DSM programs. We demonstrate that a shared-savings incentive mechanism with net benefits based only on utility costs, coupled with a modest spending cap, is, in fact, a bonus incentive mechanism in disguise. That is, it provides the utility with an incentive to maximize energy and capacity savings, not net societal benefits.

\subsubsection{Defining and Measuring Net Benefits}

In practice, net benefits are defined differently, and may sometimes be difficult to measure. Table 3-1 summarizes the components of net benefits for eight utilities with shared-savings incentives. Some utilities include environmental adders in their calculation of benefits; others do not. Estimating the cost of environmental externalities is difficult, as described extensively

Table 3-1. Definitions of Net Benefits

\begin{tabular}{|c|c|c|c|c|c|c|}
\hline \multirow[b]{2}{*}{ Utility } & \multicolumn{2}{|c|}{ Benefits } & \multicolumn{4}{|c|}{ Costs } \\
\hline & $\begin{array}{c}\text { Avoided } \\
\text { Costs }\end{array}$ & $\begin{array}{c}\text { Externality } \\
\text { Adder }\end{array}$ & $\begin{array}{l}\text { Utility Admin. } \\
\text { Costs }\end{array}$ & $\begin{array}{l}\text { Utility } \\
\text { Evaluation } \\
\text { Costs }\end{array}$ & $\begin{array}{l}\text { Utility Rebate } \\
\text { Costs }\end{array}$ & $\begin{array}{c}\text { Incremental } \\
\text { Participant } \\
\text { Costs }\end{array}$ \\
\hline PG\&E & $\gamma$ & & $\checkmark$ & & partial & partial \\
\hline SCE & $\checkmark$ & & $\checkmark$ & & partial & partial \\
\hline Midwest & $\sim$ & $\checkmark$ & $\checkmark$ & $\sim$ & $\checkmark$ & $v$ \\
\hline MECo & $\checkmark$ & $\checkmark$ & $\checkmark$ & & $\checkmark$ & \\
\hline JCP\&L & $\checkmark$ & $\checkmark$ & $\checkmark$ & $\checkmark$ & $\checkmark$ & \\
\hline Con Edison & $\checkmark$ & $\checkmark$ & $\checkmark$ & $\checkmark$ & $\checkmark$ & \\
\hline NYSEG & $\checkmark$ & $\checkmark$ & $\checkmark$ & $\checkmark$ & $\checkmark$ & \\
\hline PGE & $\checkmark$ & & $\checkmark$ & & partial & partial \\
\hline
\end{tabular}


in the literature. ${ }^{12}$ Some utilities routinely exclude monitoring and evaluation costs because they are incurred after a program has finished. Incremental customer costs are frequently omitted because they are hard to measure or estimate.

Academic economists and DSM program evaluators have begun to discuss a variety of additional costs and benefits usually omitted from net benefit calculations. ${ }^{13}$ These costs (such as consumer disutility) and benefits (such as market transformation) are controversial, in part, because they are quite difficult (if not impossible) to measure. Not surprisingly, they have not been included in the specification of net benefits for any current shared-savings incentives.

Omission of relevant costs or benefits from the definition of net benefits can, in principle, skew a utility's private interest away from the social good. In the case of environmental externalities, which are presumed to be large, the effects of omission may be very significant if they are not addressed through other means. In the case of monitoring and evaluation costs, which tend to be a modest percentage of total societal costs, the effects may be less significant. $^{14}$

\subsubsection{When A Shared-Savings Incentive is, in Reality, a Bonus Incentive}

This subsection illustrates a particularly perverse result that arises when a shared-savings incentive omits customer costs and the utility can be expected to spend its entire DSM budget. We show that, under these conditions, the shared-savings incentive is transformed into a bonus incentive.

To begin, remember our formal definition of a shared-savings incentive mechanism:

$$
\text { Shared Savings: } I=\lambda_{s} \cdot\left[A Q-\left(C_{U}+C_{P}\right)\right]-F_{s}
$$

The quantity in square brackets is the net benefit, composed of: avoided costs times energy saved (AQ), utility costs $\left(C_{U}\right)$, and participant costs $\left(C_{P}\right)$. The multiplier $\lambda_{\mathrm{r}}$ is the marginal incentive rate, and $F_{S}$ is the fixed charge. This is the formula for a "true" shared-savings incentive mechanism; however, we are concerned with "faulty" shared-savings incentive mechanisms that, for the sake of simplicity, omit participant costs:

See, for example, Ottinger, et al. (1990).

13

See, for example, Herman (1994), Braithwait and Caves (1994), and Hobbs (1991).

14 Eto, et al. (1994), recently examined the measurement and evaluation costs for 12 large commercial lighting programs and found these costs to average less than $3 \%$ of total utility costs. 


\section{Faulty Shared Savings: $I=\lambda_{s} \cdot\left[A Q-C_{U}\right]-F_{s}$}

We also need to distinguish between "small" and "large" DSM programs. We define a "small" program as one in which the utility spends up to its program expenditure cap. Such small programs have a useful incentive property: since all of the available money will be spent, utility expenditures can be treated as a negative fixed cost to the utility. Specifically, the incentive rate times this fixed cost functions like another fixed incentive charge. Intuitively, that is because the utility knows that it will spend up to its expenditure cap and simply optimizes by finding DSM programs that provide the greatest energy savings for that fixed expenditure. More formally, we assert that for small programs the following mechanism is equivalent to the previous one.

$$
\text { Small Faulty Shared Savings: } I=\lambda_{s} \cdot[A Q]-\left(F_{s}+\lambda_{s} \cdot \bar{C}_{U}\right)
$$

Note that $\bar{C}_{U}$ is the cap on program expenditure and is thus constant. Since the quantity in parenthesis is constant we can simplify by denoting it as $F_{b}$. By "equivalent" we mean that if this new incentive mechanism were used instead of the original one, there would be no change in the utility's behavior. ${ }^{15}$

Except for the fact that avoided costs depend on when (during the day and year) the savings occur, a fact that is ignored by most bonus incentive programs, avoided costs are proportional to $\mathrm{kWh}$ saved. Denoting the proportionality factors by $\mathrm{m}_{1}$ and $\mathrm{m}_{2}$, we can rewrite our shared savings formula for the final time.

$$
\begin{aligned}
\text { Small Faulty Shared Savings: } I & =\lambda_{b} \cdot[\mathrm{Q}]-F_{b} \\
\text { where } \lambda_{b} & =\lambda_{s} \cdot\left(m_{1}+m_{2}\right)
\end{aligned}
$$

Since this is exactly the formula given as the definition of a bonus incentive mechanism, this completes our demonstration that, when the definition of net benefit excludes participant costs, a shared-savings incentive mechanism is equivalent to a bonus incentive mechanism for "small" DSM programs. Since "small" simply means small enough that the utility is induced to use all available program funds, we believe this result is widely applicable. In fact, many

Assume that under the new incentive the utility acts differently. First note that if the utility acts the same it will be rewarded with the same incentive payment, therefore it will only act differently if it can achieve a higher incentive level. Since it cannot spend more, it must achieve this while spending either the same or less. To achieve it while spending the same would require generating a greater $\mathrm{kWh}$ savings, but if it could do this it would have done it under the first incentive so this contradicts our assumption that the utility behaves optimally under the first incentive. Now consider the possibility that the utility could do better by spending less. This is impossible because under the second mechanism, the utility's incentive is not increased because of reduced spending, and reduced spending cannot save more energy that an optimized program executed at the spending cap. In other words, the utility will maximize its incentive payment by acting just as it would under the first incentive. 
of the so-called shared-savings incentive mechanisms programs omit participant costs and have DSM program expenditure caps and, thus, may be bonus incentive mechanisms in disguise.

\subsection{Why the Markup Mechanism Is Dangerous, but Sometimes Appropriate}

The need to introduce additional conditions to ensure bonuses are cost effective also argues against the use of markup mechanisms, which simply reward spending. That is, the link between spending and net social benefit is even more tenuous than it is between energy savings and net social benefit. There are, however, instances when the use of markups may be justified.

Markups can be appropriate when the regulator is able to make an unbiased estimate of the net benefits of certain DSM programs, but is unable to verify the estimate. ${ }^{16}$ The regulator also must be able to verify that the utility has carried out the program. Informational programs are often cited as programs of this type. Such programs disseminate information through the media or through energy audits at individual sites. Regulators may believe that they have a rough but unbiased estimate of the savings that will result from these information programs and this may lead them to conclude that such programs are cost effective. However, it may be very costly or impossible to verify that the programs have resulted in energy savings and societal benefits. This makes it impossible to base an incentive mechanism on measured net benefit. The only possibility is for the regulator to write what economists call a forcing contract, where the utility is instructed to take a particular action (the informational program) and is given a reward for doing it, or a penalty for not doing it, that is sufficient to insure that it will be done. A markup incentive mechanism is a type of "forcing contract." It specifies how much is to be spent and how it should be spent, and promises that the costs and a specified markup (e.g. 5\%) will be reimbursed.

Markup programs present a significant danger of inefficiency because the stringent informational assumptions detailed above are often not met. When the regulator has difficulty observing the utility's actions, it will reward the utility only for costs incurred and not for actions taken. In such cases, the utility will have an incentive to act perversely. For example, the utility might turn a DSM education program into a thinly veiled public relations

16 An unbiased estimate is not necessarily easy to come by. In fact, in the circumstances in which a markup is useful the regulator will probably have to take it on faith alone that the estimate is unbiased. Nevertheless, the regulator may believe this, and wish to act on it. 
campaign. ${ }^{17}$ A second danger is the inability to verify publicly the regulator's private estimate of net benefit.

\subsection{Hybrid Incentives Reflect Multiple Regulatory Objectives}

Hybrid incentives are incentive formulas that combine two or more of the three basic incentive designs. Both MECo and PGE have hybrid incentives (see Table 3-1 and Appendix A).

MECo's incentive mechanism combines a bonus and a shared-savings incentive mechanism and adjusts the incentive level based upon actual spending levels. The bonus incentive mechanism for 1994 provides $\$ 1.53 / \mathrm{kW}$ and $0.11 \mathrm{k} / \mathrm{kWh}$ for savings that exceed 50 percent of the forecasted or expected level. The shared-savings incentive mechanism applies if the net benefits of the program are positive and simplifies to roughly 1.4 percent (after tax) of net benefits.

PGE's hybrid incentive mechanism combines a shared-savings incentive mechanism for two types of net benefits and a bonus incentive mechanism. The incentive payment, in simplified form, equals 10 percent of the net benefits using only utility costs, 10 percent of the net benefits using the total resource costs, and 5 percent of the avoided cost benefits. ${ }^{18}$ The PGE incentive, therefore, combines three regulatory objectives: net benefits (shared savings with TRC), rate impacts (shared savings with UC), and energy savings (bonus).

Hybrid incentive mechanisms reflect a regulatory preference that the utility pursue multiple objectives through its DSM programs. It is instructive to consider two situations: (1) there are multiple objectives for the entire DSM portfolio; and (2) there are different objectives for individual DSM programs within the portfolio.

In the first case (multiple objectives for entire portfolio), it is straightforward to show algebraically the resulting weight or importance given to each objective. The challenge lies in ensuring that the objectives are legitimate and that the weighting accurately reflects regulatory preferences among them. For example, the inclusion of a specific incentive to minimize rate impacts in PGE's incentive is a clearly separable regulatory objective from that of maximizing net benefits. But are they equally important to one another? Welfare economists would hold that rate impacts can be evaluated on a consistent basis with DSM net benefits, at least theoretically. Implementation of these approaches are, however,

17 Letter from. C. M. Walwyn, Administrative Law Judge of the California Public Utilities Commission (Oct. 17, 1993) (regarding proposed decision concerning Application 93-04-028 of PG\&E), "We state strongly and unequivocally that DSM funds that would otherwise have been refunded to ratepayers should not have been used for corporate image enhancement ...."

18 Utility costs include utility program costs and utility rebate costs, and total resource costs include these costs as well as incremental participant costs. 
controversial, as was discussed in measuring elements of net benefits. This is clearly an area in which individual commission preferences will vary. What is important is that these preferences are clearly communicated.

In this regard, we have one remaining concern regarding the legitimacy of saving energy (i.e., the bonus) as a regulatory objective. We have earlier argued that there is no reason to save energy simply for the sake of saving energy. Thus, given the additional requirements needed to ensure bonuses lead to the acquisition of cost-effective energy savings, combining a bonus incentive mechanism with a shared-savings incentive mechanism appears, in effect, to dilute the incentive to acquire net beneficial DSM. Would not the incentive to acquire cost-effective DSM be better indicated to the utility through a pure shared-savings incentive mechanism?

In the second case (different objectives for individual DSM programs), we believe that shared-savings incentives are generally not appropriate for achieving other regulatory objectives. For example, it makes no sense to use a DSM shareholder incentive mechanism intended to motivate a utility to maximize net social benefits to also motivate the provision of service-oriented, non-resource DSM programs. The rationale for separate versus aggregate incentives for individual DSM programs is taken up in Chapter 7. 


\section{Principles for Establishing Incentive Payments}

This chapter considers the issue of how much a utility should be paid for undertaking a DSM program. We review current practice from a variety of perspectives and then present a framework for setting incentive levels that draws on principal-agent theory from the economics literature. The theory holds that utilities incur difficult-to-measure "hidden costs" in pursuing DSM programs mandated by regulators. These costs consist of both costs associated with managerial and organizational effort, and opportunity costs associated with activities foregone by the offering of DSM programs.

\subsection{Current Practice Varies Considerably}

In Chapter 2, we summarized 1992 incentive payments and DSM expenditures for the 10 utilities in our sample (see Table 2-2). We found that some of the incentive mechanisms have been highly profitable; NYSEG and PGE earned returns of 40 and 94 percent, ${ }^{19}$ respectively, on their DSM expenditures in 1992. These high returns contrast sharply with the low returns earned by SCE (2\%), NSP (3\%), and APS ( $9 \%)$.

In Table 4-1, we present forecasted or expected shared-savings incentive payments for more recent program years (i.e., 1993 and 1994), and omit markup incentive payments and utilities with bonus incentive mechanisms. We have also calculated the ratio of expected incentive payments to expected utility expenditures, as well as the ratio of expected incentive payments to expected Total Resource Cost net benefits. ${ }^{20}$ For these calculations, we consider only the expenditures and net benefits associated with the shared savings programs.

The shared savings programs examined in Table 4-1 are also fairly profitable. JCP\&L and PGE are expected to receive returns of about 34 and 50 percent, respectively. At the same time, JCP\&L is also expected to undertake an equally large "core" program" for which it receives no incentives and PGE's incentive payments are subject to measurement and verification studies that continue for the life of the measures. For the remaining utilities,

19 Incentive payments made to PGE, however, are contingent upon ex-post measurement and evaluation, which utility staff indicate will likely reduce the incentive payment.

20 We define Total Resource Cost net benefits as the avoided cost benefits less utility administrative costs (including measurement and evaluation costs), utility rebate or incentive costs, and incremental customer costs for the shared savings program. We have not included the benefits resulting from avoided environmental externalities, nor have we included shareholder incentive payments. Utility administrative and rebate expenditures were readily available, but customer costs were more difficult to obtain. For Con Edison and NYSEG, we extrapolated customer cost figures from Utility Cost test and Total Resource Cost test ratios. 
incentive payments are expected to comprise less than 20 percent of utility expenditures. In addition, we find that the incentives account for between 8 (SCE) and 27 percent (Con Edison) of the TRC net benefits of the utilities' DSM programs.

Table 4-1. 1993 and 1994 Forecasted Shared Savings Shareholder Incentives (\$million)

\begin{tabular}{|l|l|r|r|r|}
\hline & State & $\begin{array}{c}\text { Expected } \\
\text { Shareholder } \\
\text { Incentives } \\
\text { before Taxes } \\
\text { (millions \$) }\end{array}$ & $\begin{array}{c}\text { Incentive/DSM } \\
\text { Expenditure } \\
\text { (\%) }\end{array}$ & $\begin{array}{c}\text { Incentive/ } \\
\text { TRC Net } \\
\text { Benefit }^{1} \\
(\%)\end{array}$ \\
\hline PG\&E, 1994 & CA & 12.4 & $15.8 \%$ & $16.8 \%$ \\
\hline SCE, 1994 & CA & 5.5 & $9.2 \%$ & $8.0 \%$ \\
\hline MECo, 1994 & MA & 7.2 & $10.4 \%$ & $14.8 \%$ \\
\hline JCP\&L, 1993 & NJ & 4.2 & $33.8 \%$ & - \\
\hline Con Edison, 1994 & NY & 24.7 & $19.6 \%$ & $27.1 \%$ \\
\hline NYSEG, 1994 & NY & 3.4 & $8.2 \%$ & $13.9 \%$ \\
\hline PGE, 1993 & OR & 8.9 & $50.3 \%$ & $23.1 \%$ \\
\hline
\end{tabular}

1 See footnote 20 for definition of net benefit.

\subsection{The Crucial Role of Unobservable (Hidden) Costs}

To begin, we note that the purpose of an incentive mechanism should not be to reward the utility, but to induce it to achieve regulatory objectives. This can be forgotten, and the "shared-savings incentive" can inappropriately come to be thought of as merely a plan for providing the utility with an opportunity to share the spoils between customers and shareholders. This may be its outcome but it is not its purpose. Nevertheless, it may not be possible to maximize social welfare without also making the utility better off.

The economic theory of incentives has been developed using the principal-agent model (see, for example, Laffont and Tirole 1993). In this model, the principal rewards the agent according to some formula based on observations regarding the agent and its situation. Applied to utility DSM programs, the principal is the regulator, and its agent is the utility. When the principal (regulator) has perfect information about the agent's (utility's) costs and actions, a simple "forcing contract" works perfectly. This simply specifies exactly what the 
utility must accomplish in order to obtain the reward. Markups are essentially forcing contracts. However, when the utility has useful private information (i.e., when the utility knows more about DSM than the regulator), an optimal contract always leaves the utility with some choice. This choice allows the utility to make use of its information in a way that is beneficial to both parties, and the incentive contract motivates the utility to do so.

To see the importance of unobservable costs, consider how a utility would react to a very weak incentive that was proportional to net benefit. Assume that an incentive mechanism pays the utility one percent of net benefits, and that all of the utility's DSM program costs are reimbursed and net lost revenues are compensated. Conventional wisdom suggests that, despite this, an incentive payment of only one percent would be too small to induce a utility to pursue a large DSM program. Yet, with all expenses reimbursed and net lost revenue recovered, any incentive payment at all should increase the utility's profit level. On a $\$ 100$ million DSM program with a net benefit/expense ratio of 1.5 , the utility would earn $\$ 1.5$ million for its shareholders. This is not a large sum of money, but there is no apparent reason for utility managers to ignore it.

We say "no apparent reason" because our review of current practice suggests that no utility would be motivated by the one percent incentive and we assume that, therefore, utilities have reasons to ignore it. Apparently the public utility commissions (e.g., those in NY, CA, NY, and $\mathrm{OR}$ ), which have set incentives rates ten to twenty times higher than this, also believe that small incentives would be ignored. One can only assume from this behavior that regulators believe the utility incurs additional costs, which are not apparent to regulators outside the utility and are thus not reimbursed. The issue to which we now turn is what are these costs.

\subsection{Defining and Measuring Hidden Costs}

We have asserted that a fair incentive must mitigate a utility's hidden costs. However, as indicated by their name, hidden costs are difficult to measure. In this section, we develop a classification scheme for hidden costs to identify considerations for establishing incentive payments.

We believe it is useful to distinguish two types of hidden costs and relate them explicitly to the lifecycle of DSM programs. The first type of hidden cost consists of the very real management costs associated with the additional effort and organizational changes required to implement successful programs. There are internal costs associated with managerial effort by those not directly on the DSM program payroll, with the disruption of starting new programs, and with the transfer of talented managers away from other important tasks. These costs are rarely discussed and difficult to measure. We suspect these costs will be greatest in the early phases of DSM program implementation. These costs are reflected in the shape of the hidden cost curve, which is taken up in Chapter 5 and Appendix B. 
The second type of hidden cost consists of the opportunity costs associated with utility activities foregone by pursuit of DSM programs. Opportunity costs include both uncompensated net lost revenues caused by DSM programs and foregone earnings from alternative supply investments that would have been made in the absence of a DSM program. We believe these costs increase with the scale of DSM programs and, therefore, will be greatest in the later phases of DSM program implementation.

This second type of hidden cost, while still difficult to measure, is more well-defined conceptually than the first type of hidden cost. The primary analytic issue is determining earnings comparable to those that would have been earned through the acquisition of resources in lieu of DSM. The issue is complicated because the profitability of alternatives depends on the riskiness of the alternatives and prevailing regulatory practices. For example, purchase power costs are generally passed through fuel adjustment clauses with limited regulatory review and earn no profit. Capital investments are rate-based and earned a profit based on the regulated rate of return. The profitability of these investments should in principle be captured by considering the Averch-Johnson effect. ${ }^{21}$ In the present context, the Averch-Johnson effect holds that the regulated firm will choose to invest in capital plant whenever the cost of capital is less than the rate of return because doing so will provide a positive return to shareholders. Nevertheless, no utility is guaranteed that all capital will be entered into the rate base, or that the plant will operate as planned. In other words, risk considerations underlie all resource alternatives and differ substantially for different resources. Thus, in practice, establishing truly comparable earning levels is difficult.

Some commissions have recognized these opportunity cost issues explicitly in establishing incentive payments. For example, at one point California utilities were directed to multiply the rate of return on a supply side investment by the DSM program costs to determine target incentive levels following an interim rule adopted by the California Public Utilities Commission (CPUC), which indicated that the "shareholder's rate of return on DSM programs should be no greater (and could be lower) than shareholder's rate of return on utility-constructed power plants. "22 The California approach further acknowledged that the comparative risks associated with earnings from utility-constructed power plants should be considered when compared to the earnings from DSM programs that displace the need for these plants.

See, Train 1991, for a good discussion of the Averch-Johnson effect.

22 However, the CPUC is currently reconsidering the appropriate target incentive level and other related issues, and has issued a preliminary decision allowing California utilities to retain $30 \%$ of net benefits beyond certain threshold levels (CPUC 1994d). 


\subsection{Review of Current Trends in Establishing Incentive Payments}

We return now to our review of current practice to provide some insight into the magnitude of hidden costs and to at least bound the range of incentive payments. On the low end, SCE and NSP earned incentive payments that represented only two and three percent of expenditures in 1992, respectively (see Table 2-2). Despite these rather meager rewards, the utilities undertook their DSM programs, although not without complaint. ${ }^{23}$ At the same time, the trend for these utilities has been to increase their incentives. The CPUC recently increased the share of net benefits to $30 \%$ for all of the California utilities, and NSP recently filed a request to change its incentive mechanism and to increase the expected reward to about $5 \%$ of net benefits.

On the high end, incentive levels also appear to be coming down over time. In 1992, the New York and New Jersey utilities in our sample received rewards in excess of 25 percent of their DSM expenditures and PGE could receive a reward up to 94 percent (depending upon ongoing monitoring and evaluation). See Table 2-2. For more recent program years, the incentive rates for some of these utilities have come down. For example, the New York Public Service Commission recently reduced the NYSEG's after-tax share of net benefits from $15 \%$ to $5 \%$.

23 As we will discuss in Chapter 5 , a successful incentive need not be a fair incentive in that a successful incentive can motivate utility behavior, yet not fully compensate the utility for its hidden costs. 


\section{The Importance of Marginal Incentive Rates}

This chapter addresses an important design element of DSM shareholder incentives that, we believe, has not been fully exploited by current incentive mechanisms: the marginal incentive rate. The marginal incentive is the rate of change of the incentive payment with respect to the quantity that is the basis for the incentive; graphically, it is the slope of the incentive payment curve. We begin by reviewing marginal incentive rates for seven of the utilities with sharedsavings incentives mechanisms. We then argue that the marginal rate is important because it, not the total incentive payment, determines the utility's incremental financial motivation to improve DSM program performance. Providing continuous incentives to improve performance is the whole point of an incentive program. We illustrate the motivating effect that marginal incentive rates can have with a recent example of a marginal incentive rate that was too high. We then show that an optimal rate would be 100 percent, which means that the utility would earn $\$ 1$ for every $\$ 1$ of net benefit produced. This rate is significantly higher than current practice. A high marginal incentive rate, however, does not imply a large incentive payment. In the final subsection, we show how expected incentive payments and marginal incentives can be set separately from one another through the use of a fixed charge.

\subsection{A Comparison of Shared Savings Marginal Incentive Rates}

Public utility commissions, utilities, and public interest groups continue to debate the appropriate design for DSM shareholder incentive mechanisms. For example, in a recent California proceeding, parties recommended complex, discontinuous shared-savings incentive functions as well as straight-line incentive functions, many with different marginal incentive rates and target incentive levels for different DSM programs. To put this issue in context, we compare marginal incentive rates for seven shared-savings incentive mechanisms that were in place for the 1994 program year. ${ }^{24}$

Figure 5-1 summarizes the seven shareholder incentive mechanisms graphically; the slope associated with each incentive mechanism is the marginal incentive rates (i.e., the additional incentive achieved for an additional dollar in net benefits). Figure 5-2 re-expresses the incentive payment as a function of a forecasted expected level of net benefits. This form of presentation normalizes some of the differences in DSM program size between utilities. It is important to bear in mind that the shareholder incentive mechanisms for these utilities are not strictly comparable because utilities use different definitions of net benefits (see Chapter 3).

In some cases, the incentive depends upon post-program evaluations which have not yet been completed (e.g., Midwest) and, in the case of JCP\&L, the 1994 thresholds, targets, and other program details were unavailable. In these instances, we look at earlier program years. 
Figure 5-1. Incentive Payments and Marginal Incentive Rates as a Function of Net Benefits for Seven Shared Savings Mechanisms

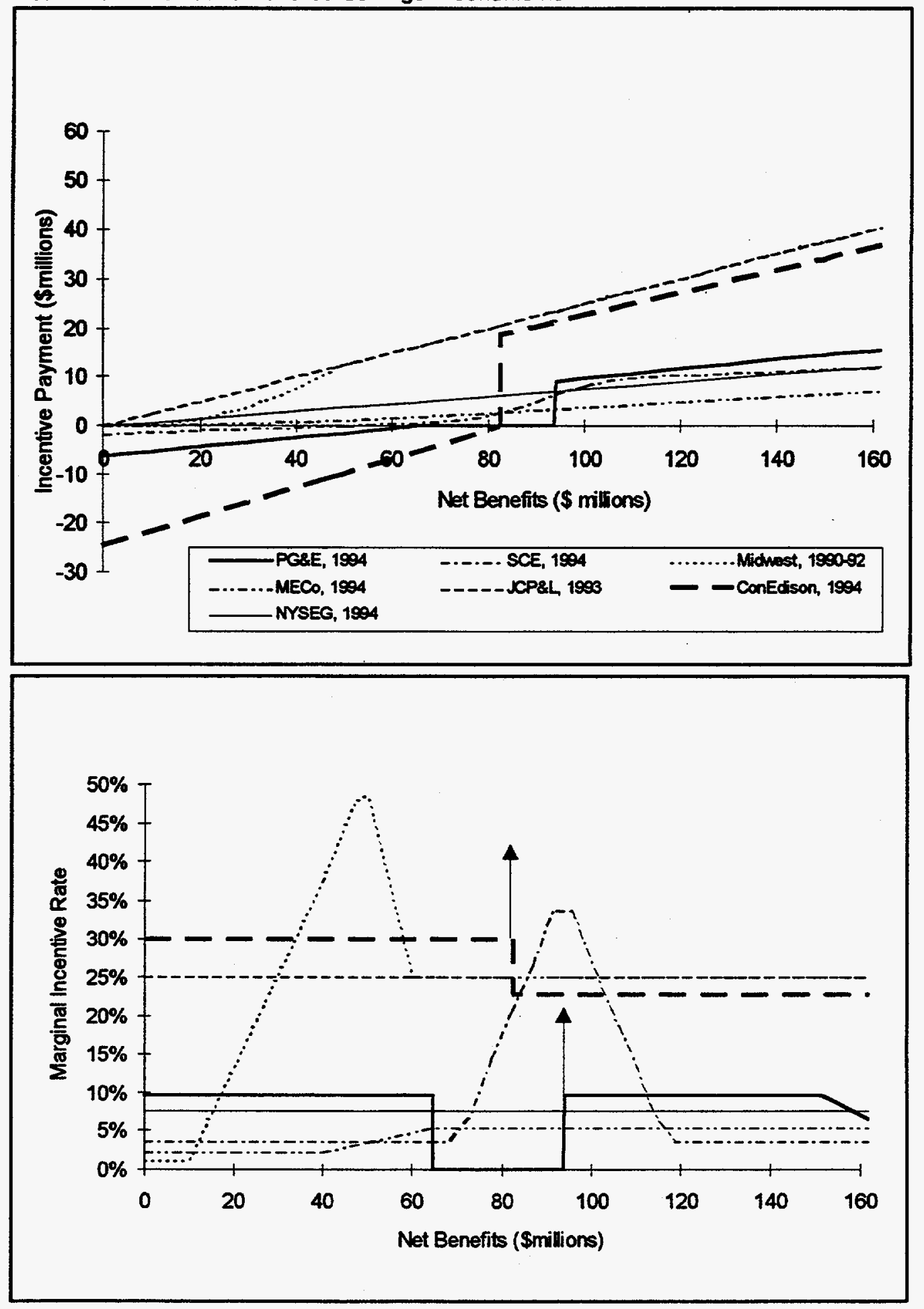


Figure 5-2. Incentive Payments and Marginal Incentive Rates as a Function of Percentage of Expected Net Benefits Achieved for Seven Shared Savings Mechanisms
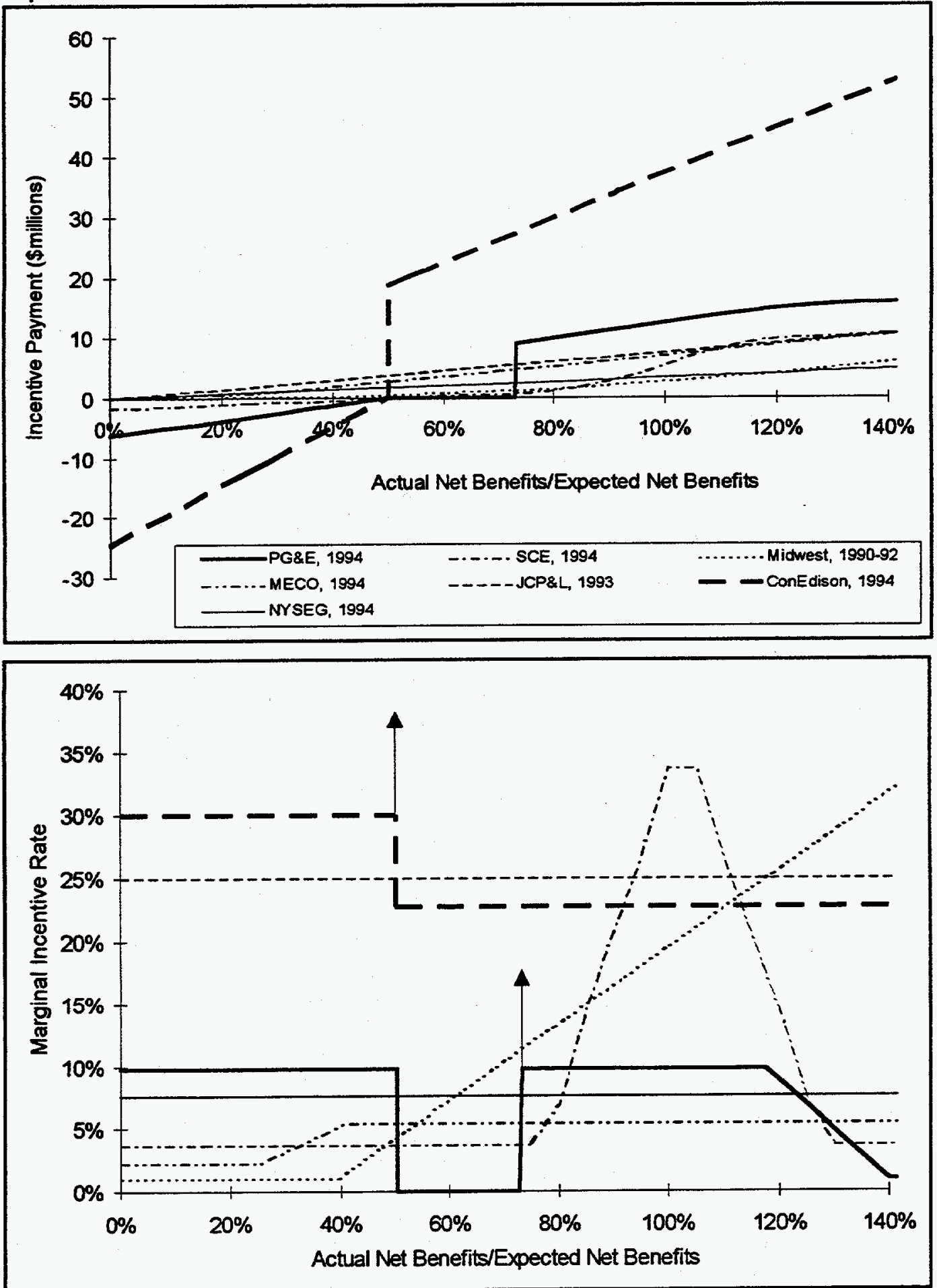
Table 5-1 summarizes the seven shareholder incentive mechanisms using the parameters described in the shared-savings incentive formula (see Chapter 3). Because few of these mechanisms are straight-line functions, Table 5-1 describes the marginal incentive rates $(\lambda)$ associated with different regions of net benefits. ${ }^{25}$

Table 5-1. Classification of Seven Shareholder Incentive Mechanisms

\begin{tabular}{|c|c|c|c|c|}
\hline Utility & State & $\begin{array}{l}\text { Region (Described in Terms } \\
\text { of Net Benefits) } \\
\text { (Smillions) }\end{array}$ & $\begin{array}{c}\text { Marginal } \\
\text { Incentive Rate } \\
\lambda\end{array}$ & $\begin{array}{c}\text { Fixed } \\
\text { Charge } \\
\text { F } \\
\text { (Smillions) }\end{array}$ \\
\hline PG\&E, 1994 & $\mathrm{CA}$ & $\begin{array}{c}\$ 181<\mathrm{NB} \\
\mathbf{\$ 1 5 3}<\mathrm{NB}<\mathbf{\$ 1 8 0} \\
\mathbf{\$ 9 4}<\mathrm{NB}<\mathbf{\$ 1 5 2} \\
\mathbf{\$ 6 3}<\mathrm{NB}<\mathbf{\$ 9 3} \\
\mathrm{NB}<\mathbf{\$ 6 2}\end{array}$ & $\begin{array}{c}1 \% \\
10 \%-1 \% \\
10 \% \\
0 \%-\infty \\
10 \%\end{array}$ & $\begin{array}{l}0 \\
0 \\
0 \\
0 \\
6\end{array}$ \\
\hline SCE, 1994 & $\mathrm{CA}$ & $\begin{array}{c}\$ 115<\mathrm{NB} \\
\$ 68<\mathrm{NB}<\$ 114 \\
\mathrm{NB}<\$ 67\end{array}$ & $\begin{array}{c}4 \% \\
4-34 \% \\
4 \%\end{array}$ & $\begin{array}{l}0 \\
0 \\
2\end{array}$ \\
\hline Midwest, 1990-92 & IA & $\begin{array}{l}\mathbf{\$ 5 0}<\mathrm{NB} \\
\mathbf{N B}<\mathbf{\$ 4 9}\end{array}$ & $\begin{array}{c}25 \% \\
0 \%-50 \%\end{array}$ & $\begin{array}{l}0 \\
0\end{array}$ \\
\hline MECo, 1994 & MA & $\begin{array}{c}\$ 65<\mathrm{NB} \\
\$ 41<\mathrm{NB}<\$ 64 \\
\mathrm{SO}<\mathrm{NB}<\$ 40 \\
\mathrm{NB}<\mathbf{} \mathbf{S 0}\end{array}$ & $\begin{array}{c}5 \% \\
2 \%-5 \% \\
2 \% \\
100 \%\end{array}$ & $\begin{array}{l}0 \\
0 \\
0 \\
0\end{array}$ \\
\hline JCP\&L, 1993 & NJ & All Outcomes & $25 \%$ & 0 \\
\hline Con Edison, 1994 & NY & $\begin{array}{l}\$ 82 \leq \mathrm{NB} \\
\mathrm{NB}<\$ 82\end{array}$ & $\begin{array}{c}23 \% \\
30 \%-\infty\end{array}$ & $\begin{array}{c}0 \\
25\end{array}$ \\
\hline NYSEG, 1994 & NY & All Outcomes & $8 \%$ & 0 \\
\hline
\end{tabular}

JCP\&L and Con Edison consistently have the highest incentive rates across various net benefit ranges. JCP\&L earns $\$ 0.25$ for each additional $\$ 1$ of net benefit achieved and Con Edison earns $\$ 0.23$ to $\$ 0.30$ for each additional $\$ 1$ of net benefit.

SCE's incentive mechanism displays the most variability in marginal incentive rates, with the highest rate occurring at 100 percent of forecasted net benefits. PG\&E has the most complex mechanism in terms of varying marginal incentive rates. Penalties are imposed below 50 percent of forecasted net benefits; the marginal incentive rate is 0 percent and infinity between 50 and 75 percent of forecasted net benefits, 10 percent between 75 and 120 percent, decreasing down to one percent at 140 percent of forecasted net benefits. 
For purposes of simplicity and clarity, we have aggregated the incentive mechanisms of PG\&E and SCE in Figures 5-1 and 5-2. In reality, the incentive functions differ for the various utility programs (e.g., residential new construction, commercial energy efficiency incentives) and, at least for SCE, the marginal incentive rates vary dramatically (see Section 5.3): $:^{26}$

\subsection{Marginal Incentive Rates Determine Performance}

Our review of current practice suggests that there is substantial variation in marginal incentive rates. We believe this variation results in part from an insufficient appreciation of the role marginal incentive rates can play in signaling the desirability of a particular level of utility performance.

In the previous chapter, we introduced the concept of hidden costs as a basis for establishing incentive payments. We now consider how hidden costs might change as a function of net benefits. Figure 5-3 presents a hypothetical hidden cost curve for a utility and two incentive functions, each with different marginal incentive rates (i.e., different slopes). ${ }^{27}$ For any level of performance, profit (or loss) to the utility is measured by the difference between the incentive line and the hidden cost curve. A profitmaximizing utility will choose a level of

Figure 5-3. Performance Depends Upon the Marginal Incentive Rate as Well as the Hidden Cost Curve

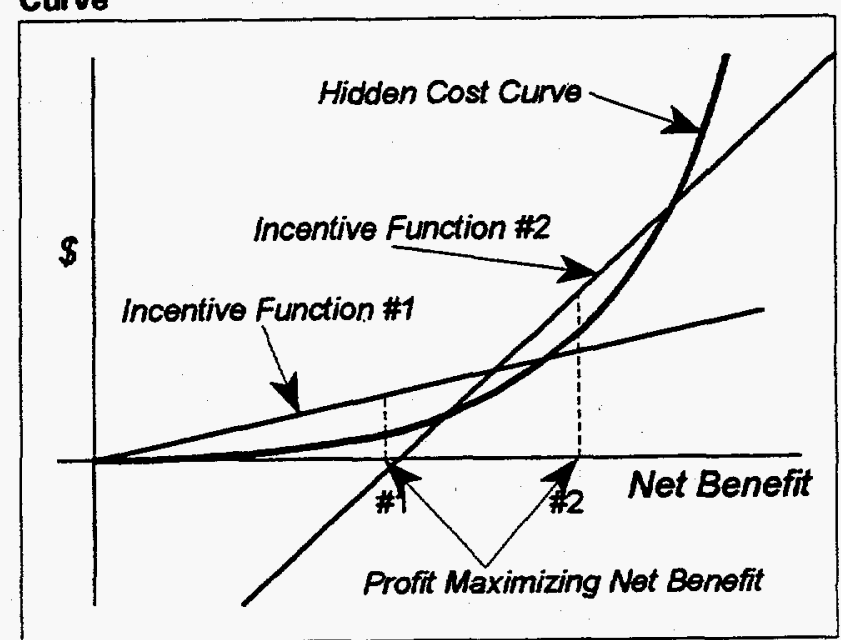
performance that maximizes the vertical distance (i.e., profit) between the incentive function and the hidden cost curve. ${ }^{28}$ This profit maximizing point occurs where the slope of the hidden cost function equals the marginal incentive rate.

26 We will take up incentive design issues associated with separate incentives for individual DSM programs in Chapter 7.

Recall that the basic rationale for offering any incentive is to provide an opportunity for a utility to trade off society's observable net benefits against its own hidden costs. In the current context, the marginal incentive rate will signal the utility to incur hidden costs up to the point where the difference between observable net benefits and hidden costs is maximized. 
This line of reasoning suggests that dead-bands are inappropriate. The marginal incentive rate within a dead-band is zero but rises to infinity at the upper end of the dead-band. (See, for example, PG\&E's marginal incentive rate in Figures 5-1 or 5-2.) Consequently, dead-bands provide no incentives for utilities to increase net benefits within the dead-band region, but significant (literally, infinite) incentives to move across to the upper-end of this region. The message sent is that the regulator is indifferent to any level of performance within the deadband region.

Figure 5-4 shows that the utility's performance level depends only on the slope or marginal incentive rate and not whether hidden costs are covered. The first incentive mechanism, which does not cover hidden costs for any level of net benefit, will induce the utility to minimize its losses. This is the same level of performance that will result from the second incentive mechanism, but, in this second case, the utility will be maximizing profit, not minimizing losses.

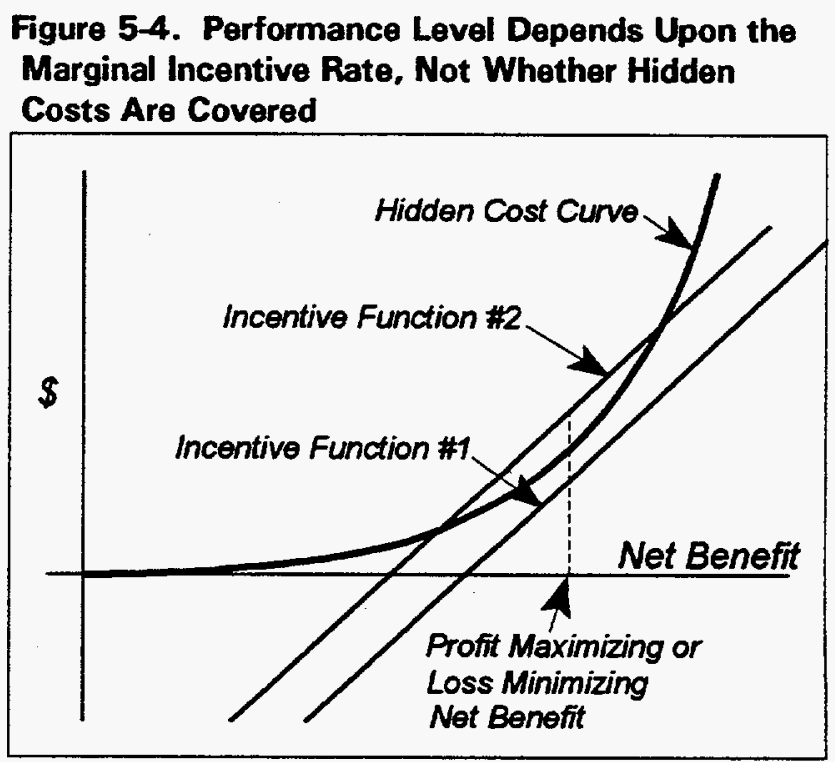

\subsection{A Recent Example of a Marginal Incentive Rate that Was Too High}

The importance of the marginal incentive rate is underscored by SCE's performance in 1993. While we aggregated SCE's shared savings mechanisms into one mechanism for simplicity in Section 5.1, SCE has separate shared-savings incentive mechanisms for each of seven individual DSM programs (see Figure 5-5). Figure 5-5 shows the incentive payment and the corresponding marginal incentive rates as a function of the percentage of expected benefits 
Figure 5-5. Edison's 1993 Incentive Payments and Marginal Incentive Rates as a Function of the Percentage of Expected Net Benefits Achieved

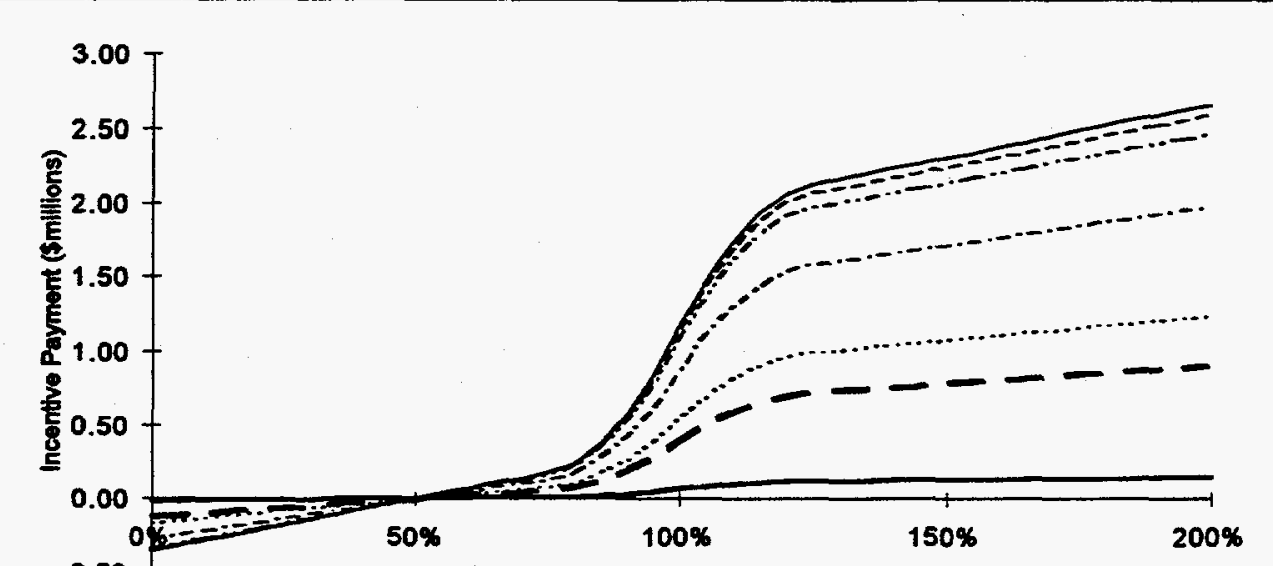

$.0 .501 \quad$ Actual Net Benefits/Expected Net Benefits

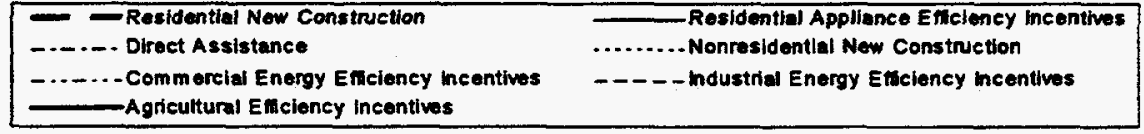

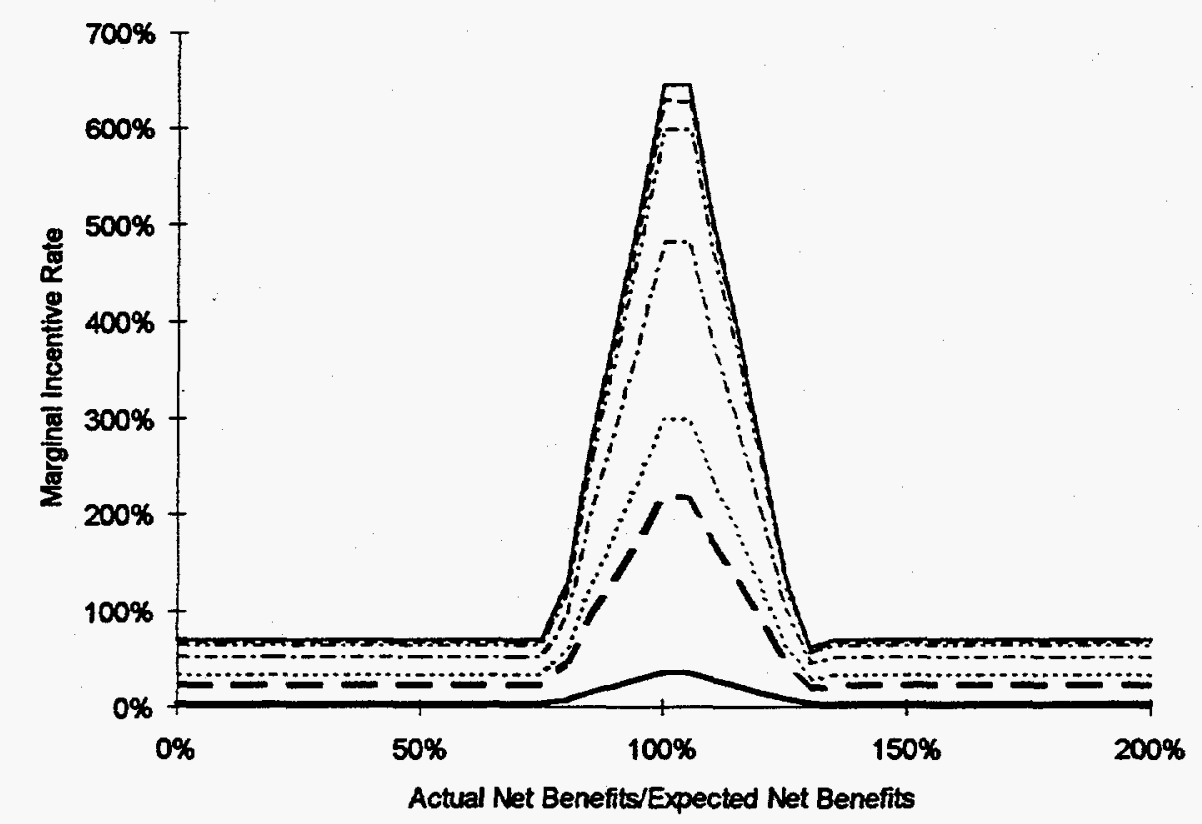


achieved for SCE's 1993 program. For example, if SCE has achieved 100 percent of the expected net benefits for its new construction program, it would have received slightly less than $\$ 0.5$ million.

But the more important figures of merit are the incentive payments and marginal incentive rates as a function of actual net benefits achieved (see Figure 5-6), not the percentage of expected net benefits achieved. Figure 5-6 illustrates that the marginal incentive rates for the residential new construction, non-residential new construction, direct assistance, and residential appliance efficiency programs are extremely high: for each additional $\$ 1$ in net benefits achieved, the utility receives a correspondingly high incremental incentive payment.

In fact, the marginal incentive rates vary from 6,015 to nearly 55,000 percent for the residential new construction program, and from 191 to nearly 2,000 percent for the nonresidential new construction program. In other words, for the residential new construction program, SCE would receive from $\$ 60$ to $\$ 550$ for each additional $\$ 1$ in net benefits!

Not surprisingly, the marginal incentive rates had the expected effect and SCE far exceeded its expected performance in 1993, particularly for those programs with high marginal incentive rates. For its residential new construction, SCE had forecast $\$ 4,000$ in net benefits, but achieved $\$ 575,000$. In the non-residential construction program, SCE far exceeded its goal of $\$ 173,000$ and achieved $\$ 10,973,000$ in net benefits. As a result, SCE filed for a $\$ 66$ million incentive payment, which far exceeded the forecasted incentive payment of $\$ 5.1$ million. ${ }^{29}$

Clearly, SCE's performance was in large measure tied up with its forecasted performance targets that, in retrospect, turned out to be quite modest; although we cannot say with certainty whether these were the result of an upturn in the business cycle, the result of aggressive marketing by the utility (in 1993, Southern California was in an economic recession) or accounting conventions that led to the inclusion of installations started in the 1992 program year in 1993 program year totals. What is important is that an incentive to low-ball these forecasts was implicitly created by the high marginal incentives offered. ${ }^{30}$ 
Figure 5-6. Edison's 1993 Incentive Payments and Marginal Incentive Rates as a Function of the Net Benefits Achieved

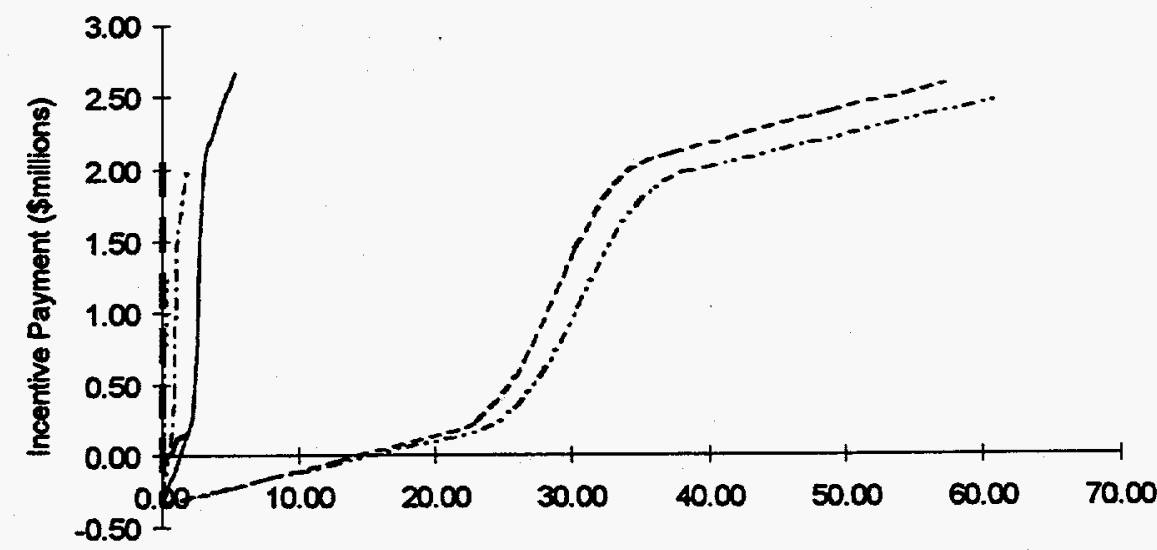

Net Benefits (Smillions)

\begin{tabular}{|c|c|}
\hline $\begin{array}{l}\text { - Residential Naw Construction } \\
-\ldots \text { - Direct Assistance } \\
\text {-...-Commercial Energy Exiciency Incentives } \\
\end{array}$ & $\begin{array}{l}\text { Residential Appliance Eliciency Incentives } \\
\ldots . . . . . . . \text { Nonresidential New Construction } \\
\ldots-\ldots-\text { - Industrial Energy Eficiency Incentives }\end{array}$ \\
\hline
\end{tabular}

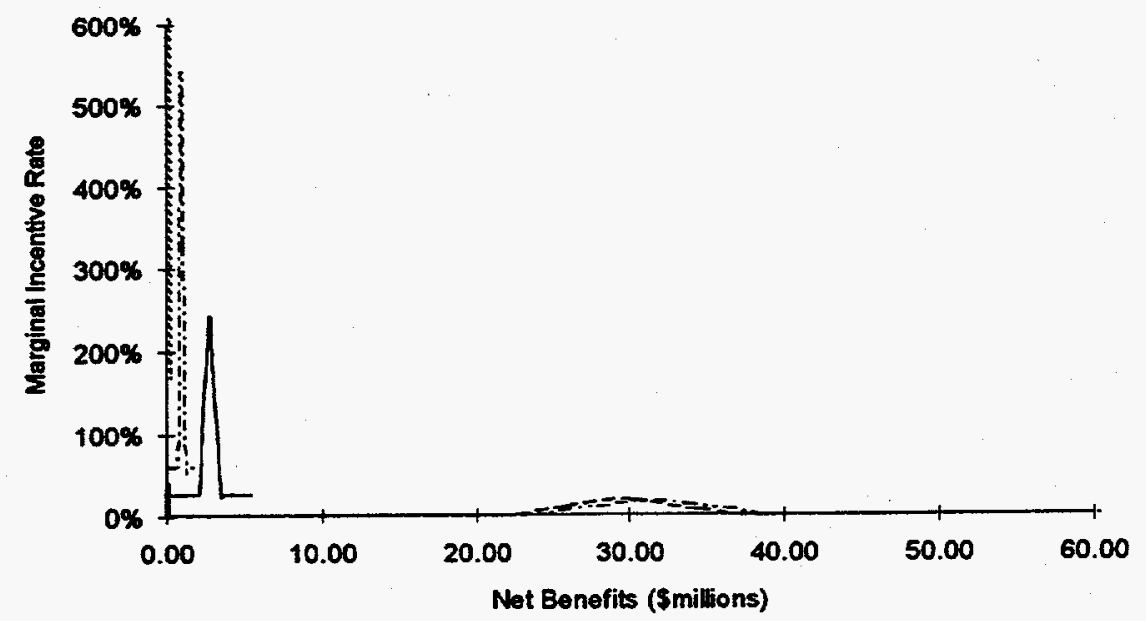




\subsection{The Optimal Marginal Incentive Rate Is 100 Percent}

We first argued from theoretical considerations and then demonstrated by example that the marginal incentive rate plays an important role in moving utilities toward a particular level of performance. We now return to theory to discuss features of an optimal incentive rate. If the marginal incentive rate is too low, some observable net benefit will not be captured, even though capturing these net benefits would still be cost effective (i.e., the observable benefits would exceed the hidden costs incurred by the utility). If the marginal incentive rate is too high, too much hidden cost will be incurred (i.e., these costs would exceed the observable net benefit).

The only way to ensure a utility has an incentive to incur hidden costs up to the point at which they equal the observable net benefit is by setting the marginal rate equal to one. That is, for each additional dollar of net benefits the utility achieves, its stock holders should be rewarded with the entire dollar. For an informal explanation of this recommendation, consider a marginal incentive rate of only $90 \&$ for each dollar in net benefits. In this case, the utility will push net benefits up to the point where the next $\$ 1$ of net benefits would cost it $91 \not$ in unrecoverable hidden costs. At this point, the utility would lose $1 \notin$ if it increased net benefits by $\$ 1$, yet society as a whole, including the utility with its hidden costs, would gain $9 \notin$ by this action, $\$ 1$ in observable net benefits less $91 \phi$ in unobservable hidden costs. (Remember that observable net benefit has already taken into account all other social costs.) Thus, with a marginal incentive rate less than 100 percent, the utility would fail to reach the level of net benefits that maximizes social welfare.

Because of the importance of this result, we present a simple algebraic proof, which also demonstrates that such an incentive greatly simplifies the DSM program monitoring requirements. Since the utility is motivated by a desire to maximize profit, the proof begins with the expression for profit, which consists of three terms. These will only cover the profit or loss that is attributable to the DSM program under consideration. The first term represents all of the costs associated with the program, including the utility's observed costs, $\mathrm{C}_{\mathrm{U}}$, the utility's unobservable hidden costs, $\mathrm{H}$, and transfer payments, $\mathrm{T}$, such as rebates, which are not social costs but which do reduce profits. ${ }^{31}$ The second term represents the utility's reimbursement for observable expenditures, and consists of $C_{U}$ and $T$. The third term is the incentive payment. This is 100 percent of observable net benefit minus some fixed term, $F$. NB is avoided cost minus all observable utility costs and all customer costs. ${ }^{32}$ The formula for profit, $\pi$, can be simplified as shown below:

31 Rebates are a loss to the utility and ultimately to all ratepayers, but they are an equal gain to the recipients of the rebates. Since the losses and gains are equal and we have no way of telling which is more socially significant, these are generally assumed to cancel.

These should include any allocative or distributional costs that result from transfer payments. 


$$
\begin{aligned}
\pi & =-\left(C_{U}+T+H\right)+\left(C_{U}+T\right)+(N B-F) \\
\text { or } \pi & =N B-H-F=\text { True Net Benefit }-F
\end{aligned}
$$

Note that while the incentive payment equals measured net benefit (minus a fixed term), the utility's profit is exactly the true social net benefit including the unobserved cost of utility effort (minus a fixed term). Thus, a profit maximizing firm will automatically maximize social value. $^{33}$ If the incentive payment were changed, however, the firm's profit would no longer equal true net benefit and the firm would be motivated to maximize something other than social value. Thus, an incentive payment rate of 100 percent of measured net benefit is the only optimal level for the incentive.

One of the greatest benefits of using a 100 percent marginal rate may be an unintentional one. With a marginal incentive rate of 100 percent, having unobservable utility costs causes absolutely no problem in equating profit with true net benefit. Since it is unnecessary to know hidden cost, why should one need to know anything about observable utility costs? After all, if any part of the utility's costs were to become hidden the above proof would still show that a marginal incentive of 100 percent is optimal. Under the proposed incentive, utility costs play no role and not need be known at all. To prove this, we add the second two terms in the first profit formula; these comprise the entire payment to the utility allowed by the regulators. The first term is a reimbursement for expenses and the second is the incentive payment, where we have written the observable net benefit as avoided cost, $A \mathcal{Q}$, minus utility cost, $\mathrm{C}_{\mathrm{U}}$, minus participant cost, $\mathrm{C}_{\mathrm{p}}$. For purposes of clarity, in the following equation, we assume that utility costs, $C_{w}$ includes only administrative costs and not transfers and that participant costs $C_{p}$, includes the full measure costs. ${ }^{34}$

$$
\begin{aligned}
\text { Payment to Utility } & =\left(C_{U}+T\right)+\left(A \cdot Q-C_{u}-C_{p}-F\right) \\
& =T+A \cdot Q-C_{p}-F
\end{aligned}
$$

Note that the payment to the utility is unrelated to the utility costs, not including rebates, $T$, which are easily monitored. This is because every dollar of cost reported by the utility is reimbursed and then deducted from the incentive payment, so the utility bears the full cost of the program.

In previous chapters, we have assumed that utility costs included rebate or transfer payments to the participant and that participant costs included the measure costs borne by the participant after taking the rebate into account. 
Additional details on the operation of the marginal incentive rate are presented in Appendix C.

\subsection{Decoupling Marginal Incentive Rates from the Total Incentive Payment}

The very high marginal incentive rates we recommend are at odds with conventional wisdom because they suggest that net transfers to shareholders may be very high. But the incentive mechanism described in the previous sections need not result in large transfers of funds from ratepayers to stockholders. Introduction of a fixed charge, F, allows the regulator to decouple the total incentive paid from the marginal incentive rate. ${ }^{35}$ Conceptually, introduction of a fixed charge can be thought of as moving the marginal incentive rate curve up or down. (See Figure 2-1.)

In principle, the utility could be assessed a fixed charge equal to the expected value of net benefit and the incentive payment would be zero for this expected level of performance. This would not disturb its incentive properties (see Section 5.2), yet would avoid large transfers of income to the utility. However, we recommend that the expected net transfer to the utility should exactly equal $\mathrm{H}$, the utility's hidden costs (see Chapter 4 ).

Decoupling marginal incentive rates from the total incentive payment also allows us to formally introduce the use of penalties for sub-par performance and performance thresholds. In the case of penalties, the introduction of a fixed charge represents a penalty to the utility at zero level of net benefit, which then decreases to zero at some positive level of net benefit (i.e., the marginal incentive crosses the horizontal axis of zero incentive payment). A performance threshold can be thought of as a zero marginal incentive below the threshold (expressed as a particular level of net benefit).

Implementing high marginal incentives rates increases the range of payments and, through the use of a fixed charge, the penalties that a utility may incur. A larger range of total payments translates to increased earnings volatility to the utility and is therefore risky. Tying a large range of total payments directly to performance, on the other hand, reduces risks to regulators of paying for benefits not received. In the next chapter, we turn to the use of other incentive design features to mitigate these risks both to the utility and to the regulator. 


\section{Mitigating Risk with Earnings and Penalty Caps}

In previous chapters, our discussions of DSM shareholder incentives did not consider the implications of risk. To recap, in a risk-neutral world, the optimal design is a shared-savings incentive mechanism, which includes a linear incentive function with a slope of one and, through the use of a fixed charge, an expected incentive payment equal to the utility's hidden costs. In this chapter, we discuss modifications to this ideal design that arise because the outcomes of DSM programs are uncertain, and both the utility and the regulator are risk averse. We begin with a review of current practices and then discuss theoretical considerations to help characterize risks more precisely. We then argue that an appropriate way to limit risk is through a reduction in the marginal incentive rate at the extremes of program performance.

\subsection{Current Applications of Earnings and Spending Caps}

Earnings caps and decreasing marginal incentive rates are two ways that regulators limit the risk of "paying too much" for the DSM programs. This might occur, for example, if a utility substantially under forecasts estimated net benefits. Among the eight utility shared-savings incentive mechanisms examined for this report, however, only NYSEG has explicit earnings caps that limit total incentive payments (see Table 6-1). At the same time, most of the programs have de facto earnings caps due to spending limits and decreasing marginal incentive rates above a certain level of forecasted net benefits. For example, PG\&E is limited to 130 percent of its approved budget and has a marginal incentive rate that decreases above 140 percent of the expected net benefits for each of its shared-savings program categories.

However, as described in Chapter 5, the spending restrictions and decreasing marginal incentive rates did not work as a de facto earnings cap for SCE. SCE was able to file for incentive payments 10 times larger than forecasted due to a combination of above-forecast performance and extremely high marginal incentive rates for its new construction programs. Examination of SCE's incentives suggests that the very formulation of this highly complicated incentive made it difficult to determine the resulting marginal incentive mechanism until it was too late.

SCE's experience is just one example of the unforeseen risks that arise when relying on untested and relatively complicated incentive mechanisms. The recognition that some risk is inevitable in all incentive mechanisms provides a strong motivation for limiting the total amount payable or the penalties assessed in the design of the incentives. 
Table 6-1. Earnings and Spending Caps for Eight Utility DSM Programs

\begin{tabular}{|l|c|l|c|c|c|}
\hline \multicolumn{1}{|c|}{$\begin{array}{c}\text { Utility, } \\
\text { Program Year }\end{array}$} & State & $\begin{array}{c}\text { Type of } \\
\text { Mechanism }\end{array}$ & Earnings Cap? & $\begin{array}{c}\text { Decreasing } \\
\text { Marginal } \\
\text { Incentive Rate? }\end{array}$ & Spending Cap? \\
\hline PG\&E, 1994 & CA & Shared Savings & no & $\begin{array}{c}\text { decreases above } \\
140 \% \text { of } \\
\text { expected net } \\
\text { benefits }\end{array}$ & $\begin{array}{c}130 \% \text { of the } \\
\text { approved budget }\end{array}$ \\
\hline SCE, 1994 & CA & Shared Savings & no & $\begin{array}{c}\text { decreases above } \\
125 \% \text { of } \\
\text { expected net } \\
\text { benefits }\end{array}$ & $\begin{array}{c}100 \% \text { of the } \\
\text { approved budget }\end{array}$ \\
\hline Midwest, 1990-92 & IA & Shared Savings & no & no & yes \\
\hline MECo, 1994 & MA & $\begin{array}{l}\text { Shared Savings' } \\
\text { Bonus }\end{array}$ & no & no & yes \\
\hline JCP\&L, 1993 & NJ & Shared Savings & no & no & yes \\
\hline Con Edison, 1994 & NY & Shared Savings & no & no & no \\
\hline NYSEG, 1994 & NY & Shared Savings & $\begin{array}{c}75 \text { basis points, } \\
\text { \$16.5 million }\end{array}$ & no & de facto cap \\
\hline PGE, 1993 & OR & $\begin{array}{l}\text { Shared Savings/ } \\
\text { Bonus }\end{array}$ & no & no & \\
\hline
\end{tabular}

\subsection{What Are the Risks Associated with DSM Shareholder Incentives?}

The use of incentives to motivate utility behavior is not risk free. For utilities, risks manifest themselves as increases in earnings volatility. For regulators, too, there are risks associated with paying too much for DSM, as well as political risks that arise from incentives which do not achieve desired outcomes. It is instructive to characterize these risks more precisely before considering the ways in which they may be mitigated.

For the utility, the risks associated with DSM shareholder incentives can be expressed by considering how the incentive design affects the total incentive payment. From this perspective, an incentive design that causes the total incentive payment to vary more than another design is more risky. Hence, for a given total incentive payment, a risk averse utility will favor the smallest possible marginal incentive rate. In the extreme, a utility will prefer a marginal incentive rate of zero, meaning that there is no risk of any deviation from some expected incentive payment. 
For regulators, there are two risks: First, there is the risk of paying too much for DSM. Second, there are political risks associated with large transfers from ratepayers to shareholders.

With respect to the first type of risk, the regulator is concerned with both the true net benefits and the incentive payment. The question is to what extent the incentive payment should count as a negative. If the regulator adopts a version of the ratepayer's perspective, the entire incentive payment should be subtracted from true net benefit, while if the regulator adopts a societal perspective, then none of the incentive payment should be subtracted. Fortunately, we can make an interesting determination without knowing the regulator's exact preference by simply assuming it lies between these two extremes. We express this assumption in a formula for the regulator's objective:

$$
\text { Regulator's Objective }=(N B-H)-\alpha \cdot I \quad \text { where } 0<\alpha<1
$$

The incentive payment is indicated by " $\mathrm{F}$ ", and in order to consider a range of possibilities we will not impose the optimal design, but will simply assume that it is some share of measured net benefit. Specifically, let

$$
I=\lambda \cdot N B-F .
$$

Substituting this into the regulator's objective function we find:

$$
\begin{aligned}
\text { Regulator's Objective } & =(N B-H)-\alpha \cdot(\lambda \cdot N B-F) \\
& =\alpha \cdot F-H+(1-\alpha \cdot \lambda) N B
\end{aligned}
$$

This shows that the regulator's objective function has a fixed component, a component that is random but uncontrollable $(H)$, and a component that is random because it depends on NB, but which is also partly controllable because it depends on the share parameter, $\alpha$. Interestingly, this third component can be made zero simply by setting $\alpha=1 / \lambda$. If the regulator adopts the ratepayer's point of view, then $\alpha=1$, and risk is minimized by choosing $\lambda=1$, which is, fortunately, the optimal marginal incentive rate. If, on the other hand, regulators take into account that incentive payments are transfer payments that do not shrink the social pie, then they will set $\alpha<1$. In this case, the risk-minimizing $\lambda$ will be greater than one. Accordingly, in no case should regulators choose a $\lambda$ smaller than one in order to minimize their own risk. Said more directly, increasing the marginal incentive payment towards 100 percent will always reduce regulators' risk.

With respect to the second type of risk, we must also acknowledge psychology and politics. It may be politically risky for the regulator to allow an outcome where both the net benefit and incentive payment are $\$ 50$ million greater than expected. As we shall discuss, no one should be disappointed with such an outcome, but human psychology being what it is, ratepayers may become upset at such a large transfer to stockholders, and this may present 
a danger to the regulator. In this case, the regulator may have a politically-based risk aversion to large deviations from the expected incentive payment.

\subsection{Addressing Risk Aversion by Tailoring Incentive Designs}

We now consider modifications to the simple linear incentive that can mitigate both of these problems. This time, instead of dividing the analysis between regulator and utility, we will distinguish between high performance and low performance.

The case of high performance is straightforward. If net benefits are higher than expected, this will present no problem for the utility since high net benefits simply result in higher incentive payments. At first glance, the regulator should also be supportive, provided the incentive design rewards net social benefits. In this situation, the additional net benefits achieved by the utility also constitute net benefits to society at large.

The regulator, however, may face political problems. Although in an economic sense the program has been more successful than anticipated, the regulator may be faulted for not anticipating the outcome and, consequently, over-rewarding the utility. To prevent such a surprise outcome, the regulator can simply put a cap on incentive payments or drastically limit the marginal incentive (and, thus, the total incentive payment) in the high performance region. This ensures that the utility has little incentive to perform much better than expected and avoids causing political embarrassment for the regulators. In the very unlikely event that the utility performs exceptionally well in spite of the earnings cap, the incentive payment will be held down by the cap, and the regulator will have secured a very "good deal" for the ratepayers.

Having addressed "upside" risk by discouraging exceptional achievement through incentive caps, we turn our attention to the "downside" risk. In fact, the downside case is the mirror image of the up-side case; however, we are this time concerned primarily with risk to the utility. In other words, assuming a marginal incentive rate of one, for the moment, underachievement by the utility presents no risk to ratepayers, since for every $\$ 1$ of expected net benefits that the utility fails to achieve, the ratepayers will be reimbursed by exactly $\$ 1$. Hence, as with the risk associated with high performance, the risk associated with low performance can simply be mitigated by a limit on incentive payments, but this time the limit is a floor and is likely to have a negative value. We refer to this as a penalty cap.

A strict penalty cap has a property that is of concern to the regulator. If the incentive mechanism has inadvertently been designed with such a low level of incentive that the utility deliberately chooses the penalty cap, it will always choose not to participate in DSM at all. This is because there is no incentive within that region to move towards higher levels of net benefit, and doing so inevitably imposes some hidden costs. Since an outcome of zero net benefit, even when compensated by a penalty payment, is a loss to ratepayers relative to any point on the 100 percent incentive line, the regulator may want to discourage this outcome. 
This can be done by replacing the cap with a reduced incentive region having a more traditional marginal incentive rate, say 15 percent. A 100 percent marginal incentive function with a 15 percent marginal incentive "cap" is guaranteed to produce as least as much net benefit as the traditional straight-line incentive function with a lower marginal rate.

To summarize, it is easy to limit the regulator's up-side risk with an earnings cap, and to limit the utility's down-side risk with a penalty cap. The magnitude of these risks increases with higher marginal incentive rates. Regulators should recognize, however, that an earnings cap removes incentives for extraordinary performance, while a penalty cap can impose some risk on the utility and the regulator. The latter problem can be reduced by using a very moderately sloped incentive region in place of a strict penalty cap. 


\section{Aggregate Versus Separate Incentive Mechanisms}

Upon close inspection, some DSM shareholder incentive mechanisms contain design elements that, in effect, lead to separate incentives for individual DSM programs. Without careful attention to their precise specification, we believe these approaches may compromise intended regulatory objectives. More importantly, we also believe these compromises can be avoided. In this chapter, we discuss issues associated with treating individual DSM programs explicitly within a DSM shareholder incentive. We begin by reviewing current practices in order to identify the net benefit reductions that some of these practices can entail. We then describe three DSM program types for which separate incentive can be justified. This discussion allows us to clarify the conditions under which separate incentives are appropriate for capturing so-called lost opportunities. Finally, we briefly discuss equity objectives, which are often used to justify separate program targets, but suggest there are ways to achieve this objective without sacrificing desirable properties of existing incentives. Appendix D provides one example.

\subsection{Separate Incentives for Individual DSM Resource Programs Will Limit Efficiency}

Separate incentive treatment for individual DSM programs generally limits a utility's flexibility to shift funds among DSM programs or to spend more than initially budgeted. This occurs when separate incentive mechanisms are created with different thresholds, penalties, and rewards. It can also occur when a single incentive mechanism is created but the utility is prohibited from substantial fund shifting among the various incentive programs (see Table 7-1). For example, MECo is allowed to modify the spending levels on individual programs up to 20 percent so long as the total spending allocated to residential programs and commercial and industrial programs does not change.

For DSM resource programs whose objective is to capture net benefits, spending restrictions will limit the very efficiency gains that the incentive mechanisms were designed to encourage. Consider an example in which a utility is required to spend $\$ 10$ million on each of two programs, one residential and one industrial. Such a constraint is almost sure to result in two programs that produce different levels of net benefit, and in particular, have different marginal net benefits. For the purposes of this example, assume that the last dollar spent on industrial DSM produces $\$ 1.50$ of net benefits, while the last dollar spent on residential DSM produces only $\$ 0.50$ of net benefit. With DSM, as in most activities, there are decreasing marginal returns to investment. Hence, assume that if only $\$ 5$ million had been spent on the residential program and if $\$ 15$ million had been spent on the industrial program, both would have had 
a marginal net benefits of $\$ 1.00$ for the last dollar spent. We can now approximate the loss caused by spending constraints.

Table 7-1. Treatment of Individual DSM Programs for Eight Utility DSM Shareholder Incentives

\begin{tabular}{|l|l|c|c|}
\hline Utility & Incentive Type & $\begin{array}{c}\text { Separate Incentive } \\
\text { Mechanisms? }\end{array}$ & Spending Flexibility \\
\hline PG\&E & Shared Savings & yes & limited \\
\hline SCE & Shared Savings & yes & limited \\
\hline Midwest & Shared Savings & no & limited \\
\hline MECo & $\begin{array}{l}\text { Shared Savings/ } \\
\text { Bonus }\end{array}$ & no & limited \\
\hline JCP\&L & Shared Savings & no & limited \\
\hline Con Edison & Shared Savings & no & yes \\
\hline NYSEG & Shared Savings & no & yes \\
\hline PGE & $\begin{array}{l}\text { Shared Savings/ } \\
\text { Bonus }\end{array}$ & yes & limited \\
\hline
\end{tabular}

Since the average marginal net benefits for residential projects when expenditures are between $\$ 5$ million and $\$ 10$ million is near $\$ 0.75$, about $\$ 3.75$ million in net benefits are lost by the cutback in residential spending. By the same logic about $\$ 6.25$ million is gained by the increase in industrial spending, for an increase in net benefits of $\$ 2.5$ million. Thus, by forcing a shift of $\$ 5$ million from industrial to residential, $\$ 2.5$ million in net benefits is lost. That is, relaxing the constraint on the originally posed $\$ 20$ million DSM program would increase the program's net benefits by $12 \%$. More extreme examples could easily be constructed including ones in which the lost value of net benefits is greater than the amount of money transferred. This point is hardly surprising since the purpose of incentives is to induce the utility to use its private information to optimize the execution of DSM programs, and funding restrictions constrain that optimization.

A more concrete example drawn from current practice also illustrates this point. In 1994, SCE expected to spend $\$ 66$ million and to achieve net benefits of $\$ 77$ million. In this example, we focus on SCE's nonresidential new construction and its commercial energy efficiency incentives programs. SCE expected to spend roughly $\$ 10$ million on each of these programs, but to achieve very different levels of net benefits. The commercial program was expected to generate $\$ 15$ million in net benefits, while the new construction program was expected to generate only $\$ 5$ million. By reallocating the entire $\$ 10$ million from the new 
construction program to the commercial program, SCE would lose $\$ 5$ million in net benefits from the new construction program, but gain $\$ 15$ million in net benefits from the commercial program, for a total increase of $\$ 10$ million. $^{36}$

\subsection{When Is Separate Incentive Treatment of Individual DSM Programs Appropriate?}

Our discussion, so far, has presumed that the primary regulatory objective is the maximization of DSM net benefits. That is, we believe it is appropriate for utilities to acquire the most cost-effective DSM resources first. We have argued that separate incentives for individual DSM programs constrain a utility's ability to pursue this strategy. We believe separate incentives for individual DSM programs can only be justified in three situations: (1) when net benefits are difficult to measure, but are known to be positive; (2) when there is a different and separately justified regulatory objective; and (3) when, under certain well-defined conditions, there are lost opportunities.

As discussed in Chapter 3, for DSM programs whose benefits are difficult to measure (e.g., information programs), markups may be the only realistic option for ensuring that the utility undertakes the program.

For DSM programs whose objective is not primarily the acquisition of a cost-effective resource (e.g., low-income or other customer-service oriented programs), shared-savings incentive mechanisms are not appropriate. It makes no sense to use a DSM shareholder incentive mechanism intended to motivate a utility to maximize net social benefit to also motivate the provision of service-oriented, non-resource DSM programs. Instead separate non-shared savings incentive mechanisms should be considered, such as bonuses.

A utility's motivation for capturing lost opportunities should be no different than its motivation for capturing all socially net beneficial DSM resources. However, if a utility takes an incorrectly myopic view of its DSM opportunities, perhaps because it falsely believes there is a high probability of early program termination, it will fail to properly avail itself of what are termed "lost opportunities." Such DSM opportunities are not actually lost, but are simply in danger of being lost, because (1) they do not currently offer the highest net benefit compared to other DSM opportunities, and (2) they will become much more expensive if not

In reality, SCE would probably achieve something less than this because, as the program expands, costs are likely to go up as participants become increasingly difficult to recruit and measures become more costly to install. Further, while restrictions on spending flexibility are the main culprit, separate incentive mechanisms with different marginal incentive rates also lead to inefficient outcomes. The problem here is that different marginal incentive rates encourage the utility to pursue DSM programs with the higher marginal incentive payments, even though the programs may not be the most cost effective. As discussed in Chapter 5, SCE's shared-savings incentive mechanism suffers from this problem, with marginal incentive rates that vary greatly among the individual sub-programs. 
done promptly. Such opportunities should be taken ahead of their natural order if their net benefit is sufficiently high, but they will be ignored by a myopic utility. On the other hand, a rational utility that correctly foresees the future of its DSM program will handle them optimally, taking them out of order exactly when it should.

If the regulator knows that its utility is incorrectly myopic, and if it cannot convince the utility to be more far sighted through assurance of DSM program longevity, then it is appropriate for the regulator to take matters into their own hands. This will generally take the form of separate programs for "lost opportunities," or of specifying that certain "lost opportunities" be bundled with other measures.

\subsection{Equity Should Be Treated Carefully as a Separate Regulatory Objective}

Separate program targets and budgets are also often justified by a concern for fairness, which is expressed as a desire to ensure that each customer class or end-use market segment has an opportunity to participate in some aspect of a utility's DSM program. The equity objective is often stated as a desire to ensure that all customers have an opportunity to receive benefits from DSM programs. While this is certainly a legitimate approach toward ensuring equity, it is, in fact, a relatively crude method that has the unfortunate consequence of constraining the utility's ability to maximize net social benefits (as discussed in Section 7.1). Moreover, since it still fails to provide any direct benefits to non-participants within the customer class or end-use market segment, it is an incomplete approach. Finally, we believe that equity concerns can be successfully and more precisely addressed in ways that do not compromise the incentive powers of the shared savings incentive mechanism. (See Appendix D for an example of how this might be done through direct allocation of DSM net benefits.) 


\section{Summary and Concluding Thoughts}

We have reviewed recent DSM shareholder incentive designs and utility performance to investigate several key design issues for DSM shareholder incentives, including: (1) the appropriate quantity to reward (e.g., net benefits, saved energy, or monies spent); (2) considerations for establishing the expected incentive payment; (3) the importance of, and optimal value for marginal incentive rates; (4) the role of earnings and penalty caps to mitigate risks to both the utility and the regulator; and (5) the justifications for aggregate versus separate incentive mechanisms. Our design recommendations are summarized in Table 8-1.

Table 8-1. Summary of Recommendations for the Design of DSM Shareholder Incentives

\begin{tabular}{|l|l|}
\hline Shareholder Incentive Design Issue & LBL Recommendation \\
\hline DSM Resource Programs & $\begin{array}{l}\text { Apply shared-savings incentives to DSM } \\
\text { resource programs }\end{array}$ \\
\hline DSM Information Programs & $\begin{array}{l}\text { Use separate incentives for individual } \\
\text { programs only when net benefits are difficult } \\
\text { to measure, but are known to be positive }\end{array}$ \\
\hline Expected Incentive Payment & $\begin{array}{l}\text { Set expected incentive payments based on } \\
\text { covering a utility's "hidden costs, which } \\
\text { include some transitional management and } \\
\text { risk-adjusted, opportunity costs }\end{array}$ \\
\hline Marginal Incentive Rate & $\begin{array}{l}\text { Use higher marginal incentive rates than are } \\
\text { currently found in practice, but limit total } \\
\text { incentive payments by adding a fixed charge }\end{array}$ \\
\hline Regulatory Risk Mitigation & $\begin{array}{l}\text { Mitigate regulator's over-payment risks from } \\
\text { under-forecasting by lowering the marginal } \\
\text { incentive rate for high performance levels }\end{array}$ \\
\hline Utility Risk Mitigation & $\begin{array}{l}\text { Mitigate earnings risks to utilities by lowering } \\
\text { the marginal incentive rate for low } \\
\text { performance levels }\end{array}$ \\
\hline $\begin{array}{l}\text { Aggregate vs. Separate Incentive } \\
\text { Programs }\end{array}$ & $\begin{array}{l}\text { Use an aggregate incentive mechanism for all } \\
\text { DSM resource programs, with limited } \\
\text { exceptions }\end{array}$ \\
\hline
\end{tabular}

Examination of utility DSM shareholder incentives provides regulators with a unique opportunity to evaluate the effectiveness of a particular type of targeted incentive regulation 
designed to motivate utilities to achieve a specific regulatory objectives. We observe that current mechanisms can probably be improved by harnessing their incentive powers more deliberately to ensure better alignment of regulatory objectives and utility financial selfinterest. Better alignment reduces adversarial confrontation and eliminates the need for regulatory micro-management.

As regulators contemplate other applications of incentive regulation, the lessons from DSM shareholder incentives are clear. Be explicit about the regulatory objective; then, when considering multiple objectives, look broadly at alternatives that have the potential to meet these objectives without compromising the incentive properties of the mechanisms. 


\section{References}

Arizona Corporation Commission 1993. "Staff Report on Resource Planning." November.

Beny, D. 1994. Personal Communication. Arizona Corporation Commission. Utilities Division.

Braithwait, S.D. and D.W. Caves 1994. "Three Biases in Cost-Efficiency Tests of Utility Energy Efficiency Programs." The Energy Journal. Vol. 15.

California Public Utilities Commission (CPUC) 1993a. Application 93-04-028. Decision 93-12-044. December.

California Public Utilities Commission (CPUC) 1993b. Proposed Decision Concerning Application 93-04-028. October.

California Public Utilities Commission (CPUC) 1994a. Application 94-05-008 et al. Decision 94-12-021. December.

California Public Utilities Commission (CPUC) 1994b. "Southern California Edison Company Submits Revised Incentive Targets for Its 1994 Demand-Side Management Shared Savings Programs and Performance Goals for Performance Adder Programs, and Requests Authorization to Shift Demand-Side Management Funds." Resolution E-3345. January.

California Public Utilities Commission (CPUC) 1994c. "Interim Opinion on DSM Shareholder Incentives: Implementation Phase." Application 94-05-008 et al. October.

California Public Utilities Commission (CPUC) 1994d. "Proposed Decision." Application 94-05-008 et al. November.

Carney, J. 1994. Personal Communication. Portland General Electric.

Consolidated Edison Company of New York Inc. (Con Edison) 1992. "Demand Side Management 1993-1994 Annual Plans and Long Range Plan." June.

Energy Information Administration (EIA) 1993. "Financial Statistics of Major Investor-Owned Electric Utilities 1992." Washington, DC: DOE/EIA. DOE/EIA-0437(92)/1. December.

Engelking, B. 1994. Personal Communication. Minnesota Public Utilities Commission.

Eto, J., A. Destribats, and D. Schultz 1992. "Sharing the Savings to Promote Energy Efficiency." Berkeley, CA: Lawrence Berkeley Laboratory. LBL-31882. April.

Eto, J., S. Stoft, and T. Belden 1994. "The Theory and Practice of Decoupling." Berkeley, CA: Lawrence Berkeley Laboratory. LBL-34555. January.

Eto, J., E. Vine, L. Shown, R. Sonnenblick, and C. Payne 1994. "The Cost and Performance of Utility Commercial Lighting Programs.” Berkeley, CA: Lawrence Berkeley Laboratory. LBL-34967. May.

Gallagher, J.T. 1991. "Building on Experience." Proceedings. 5th National Demand-Side Management Conference. Boston, MA. July 30 - August 1, 1991. Palo Alto, CA: Electric Power Research Institute (EPRD). 220-226. July. 
Hawley, B. 1994. Personal Communication. New York State Electric \& Gas.

Herman, P. 1994. "The Value Test: Its Context, Description, Calculation, and Implications." Sacramento, CA: California Energy Commission.

Hobbs, B.F. 1991. "The 'Most Value' Test: Economic Evaluation of Electricity Demand-Side Management Considering Customer Value." The International Energy Journal. 12:2:67-91.

Iowa Administrative Code (IAC) 1993. Energy Efficient Planning and Cost Review. State of Iowa. 199-235.

Iowa Utilities Board (IUB) 1994. "Final Decision and Order." Docket No. ECR-93-2. June.

Jersey Central Power \& Light Company (JCP\&L) 1992. “1992-1993 Demand Side Management Plan.” February.

Krause, F. and J. Eto 1988. "Least-Cost Planning Handbook for Public Utility Commissioners: Volume 2 - The Demand Side: Conceptual and Methodological Issues." Washington, DC: National Association of Regulatory Commissioners (NARUC). LBL-25472. December.

Laffont, J.J. and J. Tirole 1993. A Theory of Incentives in Procurement and Regulation. Cambridge, MA: MIT Press.

Lai, P. 1994. Personal Communication. Consolidated Edison of NY.

Loeb, M. and W. Magat 1979. "A Decentralized Method for Utility Regulation." The Journal of Law and Economics. 22:399.

Massachusetts Electric Company (MECo) 1993a. “1992 DSM Performance Measurement Report." Second Edition. June.

Massachusetts Electric Company (MECo) 1993b. "Offer of Settlement." December.

Massachusetts Electric Company (MECo) 1994. “1994 Conservation and Load Management Filing.” April.

Moskovitz, D., C. Harrington, and T. Austin, 1992. "Weighing Decoupling vs. Lost Revenues: Regulatory Considerations." The Electricity Journal. 5:9:58-63. November.

Nadel, S., M. Reid, and D. Wolcott 1992. Regulatory Incentives for Demand-Side Management. Washington, DC: ACEEE/NYSERDA.

Nadel, S.M. and J.A. Jordan 1992. "Does the Rat Smell the Cheese? A Preliminary Evaluation of Financial Incentives Provided to Utilities." Regulatory Incentives for Demand-Side Management. . Berkeley, CA: ACEEE. 229-254.

New Jersey Administrative Code (NJAC) 1993. State of New Jersey. 14:12-1.1 - 14:12-5.4.

New York State Electric \& Gas Corporation (NYSEG) 1992. "Demand Side Management 1993-1994 Annual Plan and Long Range Plan." June.

Northern States Power (NSP) 1993. "NSP Request for Approval of Changes to the DSM Financial Incentive Mechanism." Reference Docket No. E-002/M-90-1159. December. 
Ottinger, R.L., D.R. Wooley, N.A. Robinson, D.R. Hodas, and S.E. Babb 1990. Environmental Costs of Electricity. New York: Oceana Publications, Inc.

Pacific Gas \& Electric Company (PG\&E) 1993. "Revised Cost and Benefit Tables and Bar Graphs for DSM Programs from 1990-1993." R. 91-08-003/1. 91-08-0002. July.

Pacific Gas \& Electric Company (PG\&E) 1994a. "Advice 1800-G-A/1446-E-A; Revised Forecast of Energy Savings, Benefits, Costs, and Pre-Tax Shareholder Earnings for its 1994 Customer Energy Efficiency Programs." February.

Pacific Gas \& Electric Company (PG\&E) 1994b. "Advice 1800-G-A/1446-E-A; Revised Forecast of Energy Savings, Benefits, Costs, and Pre-Tax Shareholder Earnings for its 1994 Customer Energy Efficiency Programs." March.

Portland General Electric Company (PGE) 1992. “Advice No. 92-1." February.

Portland General Electric Company (PGE) 1994. "Advice No. 94-3." March.

Reid, M. J. Brown, and J. Deem 1993. "Incentives of Demand-Side Management." Washington, DC: National Association of Regulatory Utility Commissioners (NARUC). October.

Schlegel, J., G. Edgar, R. Prahl, M Kushler, and D. Narum et al. 1993. "Evaluation of DSM Shareholder Incentive Mechanisms." Final Report. Madison, WI: Wisconsin Energy Conservation Corporation. January.

Siebens, C. 1994. Personal Communication. Jersey Central Power \& Light.

Southern California Edison (SCE) 1993a. "Advice No. 995-E; Demand Side Management Programs 1992 Incentive Earned." March.

Southern California Edison (SCE) 1993b. “Advice No. 995-E-A; Demand Side Management Programs 1992 Incentive Earned." November.

Southern California Edison (SCE) 1993c. “Advice No. 1015-E; Revised Incentive Targets, Request for Authorization to Shift DSM Funds, and 1994 Program Changes." October.

Southern California Edison (SCE) 1994a. "Advice No. 1015-E-A; Revised Supporting Documentation Table C for Advice Letter 1015-E-A." April.

Southern California Edison (SCE) 1994b. “Advice No. 1015-E-A; Revised Attachment 1." April.

Southern California Edison (SCE) 1994c. "Application for 1993 DSM Earnings Claim." May.

Stof, S. and RJ. Gilbert 1994. "A Review and Analysis of Electric Utility Conservation Incentives." Yale Journal on Regulation. 11:1: Winter.

Train, KE. 1991. Optimal Regulation, The Economic Theory of Natural Monopoly. Cambridge, MA: MIT Press.

Violette, D. and J. Raab 1994. "Regulating DSM Program Evaluation: Policy and Administrative Issues for Public Utility Commissioners." Washington, DC: National Association of Regulatory Commissioners (NARUC).

Zeman, A. 1994. Personal Communication. Midwest Power. 


\section{Descriptions of Ten Utility Incentive Programs}

This appendix describes the shareholder incentive programs of the ten utilities discussed in this report. Citations for the utility information contained in this report are included at the end of each section.

\section{A.1 Arizona Public Service (APS)}

The Arizona Public Service Commission authorized a bonus incentive mechanism for APS in December 1991 (Decision No. 57649). The incentive is specified in terms of \$ per $\mathrm{kW}$ saved and is equal to the present value of the deferred return on investments in supply-side resources. For 1992 , the net present value of the incentive was approximately $\$ 104 / \mathrm{kW}$ in net present value terms. Currently, APS receives incentives for its commercial lighting and its residential new construction programs but not for its pilot study of variable speed drives and its educational program, "In Concert with the Environment." APS recovers the incentive over 20 years with the incentive rate declining over this time like the interest on a mortgage. In addition, APS receives net lost revenues on its lighting and residential new construction programs. Total program costs, including utility expenditures, shareholder incentives, and net lost revenues were capped at $\$ 4$ million for 1992, but the cap does not include the future stream of incentive payments associated with the 1992 DSM program. (Arizona Corporation Commission 1993; Berry, 1994.)

\section{A.2 Pacific Gas \& Electric (PG\&E)}

The California Public Utilities Commission (CPUC) approved PG\&E's shared savings and markup incentive mechanisms in December 1992 (Decision 92-12-057). The shared savings mechanism for the 1993 and 1994 programs is similar to the previous mechanism in that it is a nonlinear function of net benefits. PG\&E is penalized if net benefits fall below 50 percent of the expected figure and receives no incentives if net benefits fall between 50 and 75 percent of expected levels. These thresholds apply to all of PG\&E's "resource programs" except for its residential appliance efficiency program, which has slightly lower thresholds of 45 and 65 percent. Above these thresholds (75\% for other programs and $65 \%$ for residential appliance efficiency programs), PG\&E will receive a fixed shared savings rate of net benefits up to about 120 percent of expected net benefits. After this point, the marginal incentive rate drops linearly to 10 percent of the fixed shared savings rate at 140 percent of expected net benefits and then continues at this lower level. The fixed shared savings rate was 5.2 and 9.6 percent for 1993 and 1994, respectively. The markup mechanism applies to PG\&E's "performance adder" programs, and the markup varies from 5 to 12 percent, before taxes. 
Beginning in 1994, PG\&E (and other California utilities) will recover shareholder incentives in four separate payments. The first payment will be made after the CPUC confirms program participation and spending levels; subsequent payments will be made after ex-post load impact and performance and retention studies are completed. Although PG\&E does not have a net lost revenue mechanism, the utility does have a decoupling mechanism, the Electric Revenue Adjustment Mechanism (ERAM), which serves a similar function. In October 1994, the CPUC adopted new shareholder incentive mechanisms for the three California investor-owned utilities. Unless otherwise directed, these mechanisms will be in effect through the 1997 program year. (CPUC 1993a; CPUC 1994b; CPUC 1994c; CPUC 1994d; PG\&E 1993; PG\&E 1994a ; PG\&E 1994b.)

\section{A.3 Southern California Edison (SCE)}

The CPUC approved SCE's "S" shaped shared savings and its markup incentive mechanisms in December 1991. The shared savings mechanism imposes penalties for very low net benefits (i.e., less than $50 \%$ of those forecasted) and employs very low incremental incentive rates at very low as well as very high net benefits and a very high incentive rate near forecasted net benefits. The mechanism is linear below 75 percent and above 125 percent of forecasted net benefits, and parabolic between 75 and 125 percent. The mechanism is designed to allow SCE to earn between 9 and 11 percent times its program cost if it reaches 100 percent of its saving goal. The shared savings curves are uniquely specified for seven of SCE's programs based on their cost effectiveness, but we aggregated them to the utility level for purposes of simplicity in Chapter 5. SCE's markup mechanism applies to its residential energy management services program and its nonresidential energy management program. The markup is 2 percent on the former and 5 percent on the latter.

Like PG\&E, SCE will recover its shareholder incentive in four payments based on confirmation of program costs and participation levels and the results of ex-post measurement and evaluation. In addition, SCE also has a revenue decoupling mechanism which is meant to address the disincentive to pursue DSM because of lost revenues. SCE's new shareholder incentive mechanisms will be in effect beginning in 1995 and, unless otherwise directed, through the 1997 program year. (CPUC 1994a; CPUC 1994b; CPUC 1994c; CPUC 1994d; SCE 1993a; SCE 1993b; SCE 1993c; SCE 1994a; SCE 1994b; SCE 1994c.)

\section{A.4 Midwest Power (Midwest)}

The Iowa Utilities Board issued rules governing implementation of shared savings incentive mechanisms in April 1991 (Docket No. RMU-92-14). Under these rules, Midwest Power, the successor corporation by merger to Iowa Power, will earn incentives if the benefit/cost ratio for its programs exceeds 1.25 . The incentives and penalties are calculated using the following formulas: 


$$
\begin{aligned}
& \text { Incentive }=0.20 *(\text { Actual Benefit/Cost Ratio }-1.25) * \text { Net Societal Benefits } \\
& \text { Penalty }=0.05 *(100 \%-\% \text { of Budget Expended }) * \text { Planned Net Societal } \\
& \text { Benefits }
\end{aligned}
$$

The incentive is capped at 25 percent of net societal benefits, and the penalty is capped at 15 percent of forecasted net societal benefits. Because the structure of the incentive mechanism depends on ex-post assessment of the actual benefit/cost ratio, we confine our analysis to the 1990-1992 program years, for which these data are available. Midwest proposed that incentives be grossed up to account for taxes, but the Iowa Utilities Board denied this request.

Midwest Power recovers incentives as part of its cost recovery filing. The Commission allows the utilities to recover net lost revenues if the utility can demonstrate that DSM reduces revenues below test year revenues. (Iowa Administrative Code 1993; Iowa Utilities Board 1994; Zeman 1994.)

\section{A.5 Massachusetts Electric Company (MECo)}

MECo's incentive mechanism combines a bonus mechanism (the "maximizing incentive") with a shared savings mechanism (the "efficiency incentive" and "inefficiency penalty"). The maximizing incentive rewards the utility a bonus per unit of demand and energy savings in excess of 50 percent of the expected savings. ${ }^{37}$ Upward and downward adjustments are also made to these figures based on actual spending and budget levels. The efficiency incentive is given by a complex formula but reduces to a standard shared savings mechanism. ${ }^{38}$ The penalty mechanism is also given by a somewhat complex formula but reduces to actual spending minus actual value. In other words, the penalty equals 100 percent of negative net benefits. All incentives are grossed up to account for taxes.

37 The "maximizing incentive" for 1994 takes the following form:

$=\$ 1.53 \times$ [Actual $\mathrm{kW}-\mathrm{Yrs}$ of Lifetime Demand Savings $-(($ Actual Spending/Spending Budget $) \mathrm{x} 1 / 2$ of Expected $\mathrm{kW}-$ Yrs of Lifetime Demand Savings)] + \$0.00111 x [Actual $\mathrm{kWh}$ of Lifetime Energy Savings ((Actual Spending/Spending Budget) $\times 1 / 2$ of Expected Lifetime $\mathrm{kWh}$ Savings)]

The "efficiency incentiven for 1994 takes the following form, where $\$ 66,395,100$ is the budget allocation:

$=[(($ Actual Value/Actual Spending $)-1.0) /(3.39-1.0)] \times \$ 2,169,809 \times($ Actual Spending/\$66,395,100)

which simplifies to:

$=[\$ 2,169,809 /(\$ 66,395,100 \times(3.39-1.0))] \times[$ Actual Value - Actual Spending], or $=0.01367 \times$ Net Benefits 
Shareholder incentives are recovered after confirmation of program expenditures but are subject to reconciliation in future years. Although the Massachusetts Department of Public Utilities provides no treatment of lost revenues, MECo, through its generating affiliate, New England Power System, is compensated for lost revenues through rate cases at FERC, which has the same effect as decoupling (Eto, Destribats, and Schultz 1992). (MECo 1993a; MECo 1993b; MECo 1994.)

\section{A.6 Northern States Power (NSP)}

In December 1993, NSP proposed a shared savings and a markup mechanism to replace the shareholder incentive mechanisms currently in place, but the Minnesota Public Utilities Commission deferred action on this request. NSP has two separate shareholder incentive mechanisms currently in place. The first applies to NSP's "direct-impact" projects in the residential, commercial, and industrial sectors, and increases the return on equity by up to 5 percent on the ratebased DSM expenditures, depending upon the $\mathrm{kWhs}$ saved. For example, in 1992, NSP saved 116 percent of the planned $\mathrm{kWh}$ and, as a result, earned a 5 percent increase in the ROE for its ratebased program expenditures. ${ }^{39}$ The second mechanism, which applies to NSP's audit, seminar, and information programs, works in a similar fashion but depends upon participation levels. In 1992, NSP achieved a participation level of 78 percent (weighted by cost per program) and, as a result, earned an ROE 2.82 percent higher for the ratebased expenditures associated with these programs. In addition, NSP also has research, planning, and development expenditures for which the utility receives no incentives. NSP is the only utility in our sample that is not compensated for lost revenues, although the Commission recently ruled that NSP could collect $50 \%$ of the lost revenues for 1994 (NSP 1993; Engelking 1994).

\section{A.7 Jersey Central Power \& Light (JCP\&L)}

The New Jersey Board of Regulatory Commissioners approved JCP\&L's shared savings incentive mechanism in September, 1992 (Docket No. EE92020103). The shared savings mechanism allows JCP\&L to retain 25 percent of the net benefits, which are defined as avoided costs plus a $2 \notin / \mathrm{kWh}$ environmental adder less utility program costs and a portion of the fixed cost revenue erosion (N.J.A.C 14:12-3.2) The fixed cost revenue erosion is determined on a per-unit basis by dividing total test year retail revenues minus the sum of test year gross receipts and franchise taxes, fuel costs, and other variable costs approved by the board by the total test year retail sales.

The shared savings incentive mechanism applies only to JCP\&L's performance-based program costs and not to its core program costs. The incentive will be estimated over the life of the 
DSM program and recovered over a three-year period but subject to reconciliation based upon ex-post measurement and evaluation. JCP\&L also has a net lost revenue adjustment mechanism. (JCP\&L 1992; New Jersey Administrative Code 1993; Siebens 1994.)

\section{A.8 Consolidated Edison (Con Edison)}

Con Edison's incentive mechanism for 1993 - 1994 was approved by the New York Public Service Commission on April 14, 1992 (Opinion No. 92-8, Case 91-E-0462) and replaced an "ROE adjustment mechanism" that applied in 1991 and $1992 .{ }^{40}$ The new shared savings mechanism allows Con Edison to earn 15 percent of the net resource savings (NRS) if it achieves 50 percent of the NRS goal but penalizes the utility for shortfalls below the 50 percent threshold. All incentives (but not penalties) are grossed up to account for taxes, which results in a marginal incentive rate of 23 percent if we use a 34 percent tax rate.

The NRS goal for 1994 is $\$ 164.7$ million although the commission may update this figure based upon new avoided costs and the DSM program approval process. Con Edison is allowed to capitalize and amortize its DSM program costs over five years. In addition, in April 1992, the commission approved a revenue decoupling mechanism that replaced an earlier net lost revenue adjustment mechanism. (Con Edison 1992; Lai 1994.)

\section{A.9 New York State Electric \& Gas (NYSEG)}

The New York Public Service Commission recently modified NYSEG's incentive mechanism, reducing the utility's share of net resource savings (NRS) from 15 to 5 percent. Incentives are grossed up to account for taxes, meaning that the marginal incentive rate before taxes is about 8 percent if we assume a 34 percent tax rate. NYSEG recovers incentives annually in its fuel adjustment clause, with annual reconciliation. The commission has also approved a partial revenue decoupling mechanism for the utility. (NYSEG 1992; Hawley 1994.)

\section{A.10 Portland General Electric (PGE)}

The Oregon Public Utilities Commission approved PGE's shared savings incentive mechanism in January 1991. The total incentive payment is the product of the incentive rate (IR) times the difference between the annual savings and the commission-specified benchmark. The incentive rate depends upon the long-run incremental costs (LRIC), utility program costs (UPC) and total resource costs (TRC) and is specified using the following formula:

40 The return on common equity (ROE) adjustment mechanism adjusted Con Edison ROE based upon performance in terms of energy saved and net resource savings. The incentive was limited to an upward adjustment of 48 basis points and a downward adjustment of 25 points. 


$$
\mathrm{IR}=\mathrm{A}[(0.25 * \mathrm{LRIC} / \mathrm{kWh})-(0.10 * \mathrm{UPC} / \mathrm{kWh})-(0.10 * \mathrm{TRC} / \mathrm{kWh})]
$$

where $A$ is the present value of the 20-year annuity of the yearly incentive rate.

PGE collects 25 percent of the incentive after verification of program costs and receives the remaining amount in equal payments over a 15-year period, subject to ex-post measurement and evaluation. PGE also has a lost revenue adjustment mechanism. (PGE 1992; PGE 1994; Carney 1994.) 


\section{What Is the Shape of the Hidden Cost Curve?}

Hidden costs are by definition not well known to regulators; regulators probably know very little about the shape of the hidden cost function, h(NB), which shows how hidden costs increase as a utility produces more net benefit at a given fixed level of observable cost. We divide all possible shapes into two categories. Remember that our recommended incentive mechanism rewards net benefit at a marginal rate of one. First consider the category of functions in which $h(\mathrm{NB})$ remains at a slope less than one for large values. Figure B-1 displays two such possibilities. In the first of these cases, the function starts with a slope less than one, and in the second it starts with a slope greater than one.

In either case, when we consider the utility's behavior, we see that in order to maximize profit, the utility should increase NB without limit. This would be an excellent outcome for both the utility and the regulator. But such a possibility is unreasonable because NB is limited by the current total cost of electricity production. Eventually (at least by the time all electricity has been conserved), hidden costs will become extraordinarily high. Remember that non-hidden costs are strictly limited by the regulator, so all increases in performance come from increasing hidden cost.

The second category of hidden cost functions have slopes that $d o$ not remain less than one as the net benefit increases towards its limit. These functions can have an infinite variety of beginnings, but if any amount of reasonable energy savings are possible, the function will at some point be below the diagonal line depicted in the next figure. We assume that there is some worthwhile DSM and that, as we near 100 percent conservation, increasing net benefit becomes very costly. With these assumptions, the hidden cost function
Figure B-1. Category 1 Functions

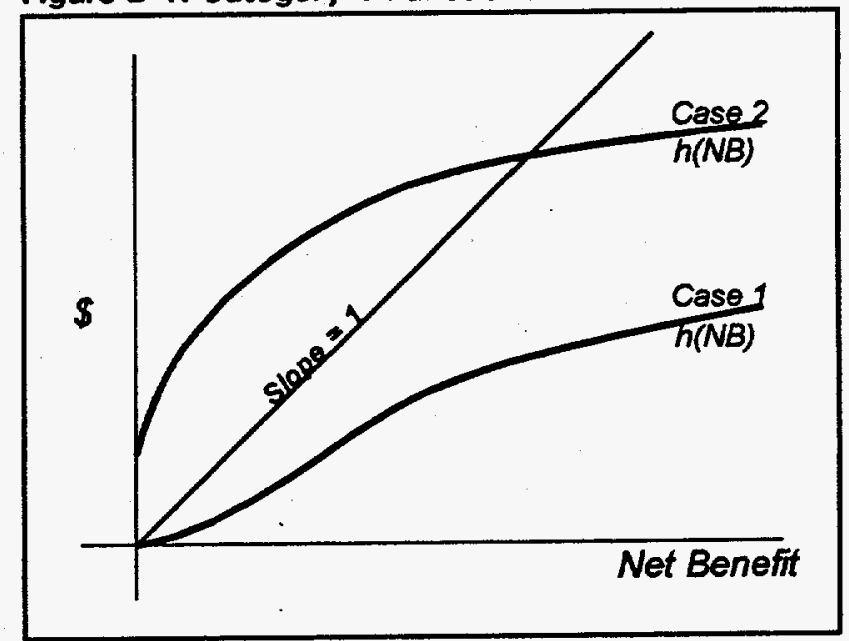

Figure B-2. A Category 2 Function

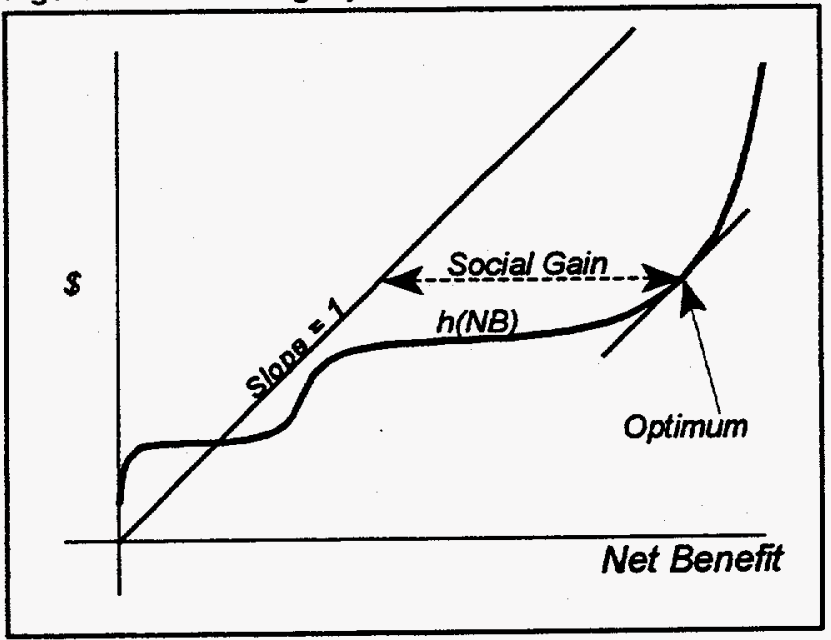


must essentially look like Figure B-2, and a less-than-maximal value of net benefit will maximize the utility's profit. If the incentive function has a slope of one, this choice will be socially optimal. Because we know very little about the wiggles at the beginning of the hidden cost function and because they play no role in the final outcome, we will normally draw the hidden cost function with a simple shape for convenience.

To reinforce our point, it should be noted that even in the (impossible) category 1 , an incentive with a slope of 1 still motivates optimal behavior. No shape of the hidden cost function would cause the regulator to prefer an incentive function with a different slope. The only difficulty that can arise is an incentive function that is too low

Figure B-3. Incentive Function Too Low Compared to Hidden Cost Function

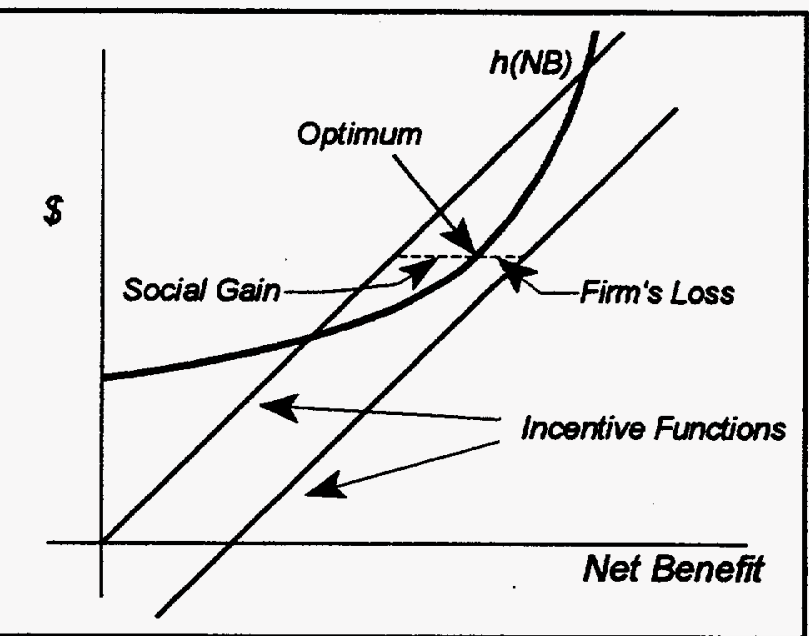
relative to the hidden cost function. See

Figure B-3. In this case we can see that if the incentive function is too low relative to the hidden cost function, the utility will suffer. Nonetheless, making the slope of the hidden-cost function one still leads to the social optimum even though the social gain is not distributed fairly. 


\section{On the Operation of a $100 \%$ Marginal Incentive Rate for Shared Savings}

To explain the use and benefits of a high marginal incentive rate, we use the following example. We assume that a utility has a shared savings program with a cost cap of $\$ 10$ million on utility expenditures, and, for simplicity, a flat incentive rate of 15 percent of net benefits; both are typical in the industry. To determine how the utility's behavior would change with a different incentive mechanism, we have to assume a particular hidden cost function; without an assumption about hidden costs, there would be no way to compare incentive functions and thus no way to choose one over another. Having very little data to help us in choosing a realistic hidden cost function, we will choose one that is convenient and seems plausible:

$$
H=N B^{3} / 675
$$

We have chosen a cubic function because it is less optimistic about the benefits of a 100 percent incentive than a quadratic, and because its rapid acceleration of costs as net benefits increase is probably realistic. We can now determine the utility's behavior with a typical 15 percent incentive. Differentiating with respect to net benefits (NB), we find:

$$
H^{\prime}=N B^{2} / 225
$$

As can be seen from Figure $\mathrm{C}-1$, the utility's profit maximizing $\mathrm{NB}$ is achieved when $\mathrm{H}^{\prime}=0.15$. Solving for profit-maximizing, we find $\mathrm{NB}^{*}=\$ 5.8$ million, which implies a hidden cost of $\$ 0.3$ million.

Before moving on to the suggested 100 percent marginal incentive rate, consider a less radical change in the incentive mechanism: a linear mechanism with a slope of 0.5 , passing through the operating point of the 15 percent mechanism. This means that if the utility chooses to produce the same net benefit that it would under the 15 percent mechanism, it will receive exactly the same incentive payment. One might

Figure C-1. Hidden Costs with Traditional (15\%) and Improved (50\%) Incentives. (Slopes have been exaggerated by a factor of 2 for clarity.)

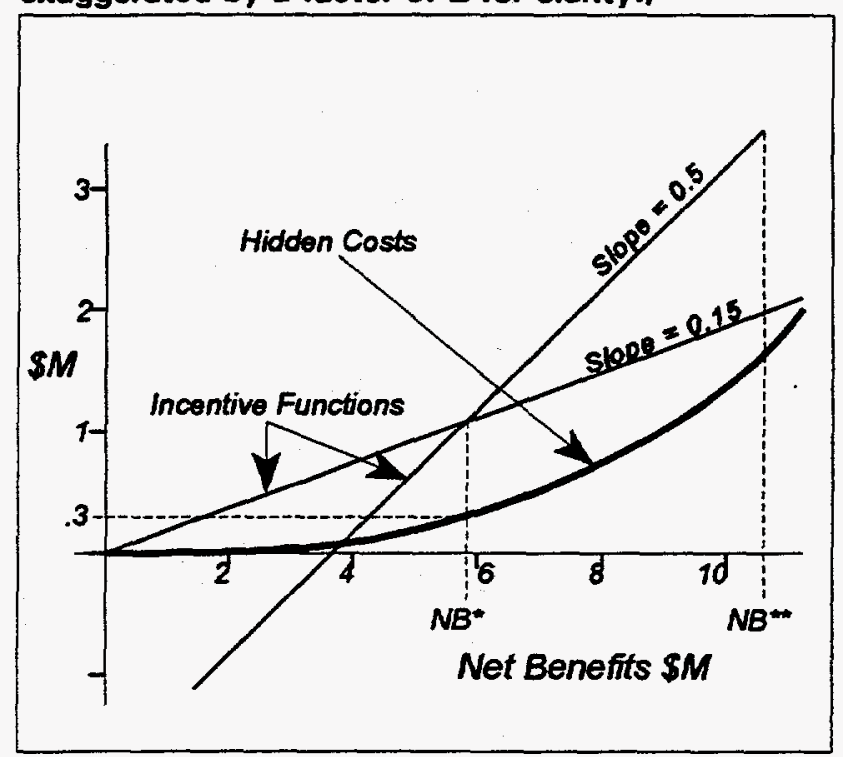
imagine this being accomplished by implementing the 15 percent mechanism for one year, observing the utility's performance, and 
then drawing the incentive line through that operating point when constructing the second year's mechanism.

The new 50 percent mechanism has the desirable property of making both the utility and its ratepayers better off, provided that circumstances have not changed. If hidden costs have remained the same, then the greater incentive will motivate the utility to incur more hidden costs and generate more net benefits than did the original incentive. Because the ratepayers give away only half of the additional net benefits generated, they also benefit by an increase in net benefits. The utility can always do as well under the new mechanism as under the old, so it will not alter its behavior unless it will be better off. Therefore, the utility will find its increase in effort profitable.

Of course this trick could be used a third time by again increasing the slope. This procedure remains beneficial up to the point where the incentive function has a slope of one. There are two problems with such a sequential approach. First, the hidden cost function may shift from year to year, and, second, even though it increases net benefit retained by ratepayers at every step, it may still allow the utility to capture excessive rents. This second problem is especially acute if the utility acts strategically during the adjustment process.

The dynamics of such an adjustment process are worth studying but are beyond the scope of this paper, so for now we simply observe that one can increase the slope of the incentive function until it reaches 100 percent and simultaneously increase the well being of each party, provided the underlying hidden cost function is fixed.

We now examine the effect of using the optimal incentive mechanism with a 100 percent marginal rate. This mechanism is shown in Figure C-2 and consists of a straight line with a slope of one passing through the hidden cost function at the exact point where its slope is one. Note that the optimal mechanism induces far more effort, as indicated by hidden cost, on the part of the utility: $\$ 5$ million rather than $\$ 0.29$ million. The result of this 17 fold increase in effort is to raise net benefits from $\$ 5.8$ million to $\$ 15$ million, a substantial increase but much less dramatic than the rise in Figure C-2. Effect of a $100 \%$ Marginal Incentive Rate hidden costs.

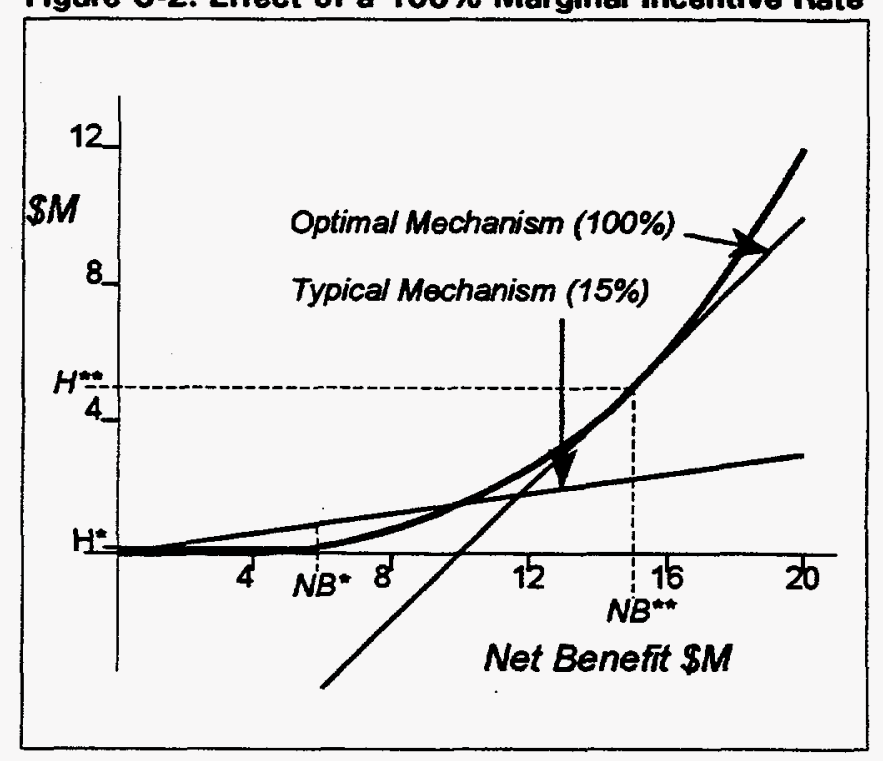


For the utility, the net result is a small loss in overcompensation than was received under the original incentive (and not present with the new incentive function). For the ratepayer, there is a net gain equal to the difference in height between the two incentive functions at NB*, the traditional operating point. This difference is $\$ 5.06$ million.

Finally, we examine the consequences of making an incorrect assumption about the hidden cost function. For this purpose, we also modify our incentive mechanism with an incentive cap at $\$ 6$ million more than the expected incentive payment and a penalty cap at $\$ 6$ million less. Two possible mistakes in the hidden cost function will be considered; first, that it is half as high as we imagined, and second that it is twice as high (see Figure C-3).

Without the caps, the utility would generate the socially optimal NB in both cases, but it would suffer more of a loss in the high-cost case and make additional profits in the lowcost case. The high-cost case is particularly interesting. The cap has not been set particularly low; therefore, if it was a fixed cap, as discussed previously, the utility would have chosen a NB that was zero or even negative because this would have created less of a loss than operating at the point where the hidden cost function has a slope of 1 and NB is $\$ 10.6$ million. Instead of a fixed cap, we have implemented a

Figure C-3. The Effect of Errors in Estimated Hidden Cost

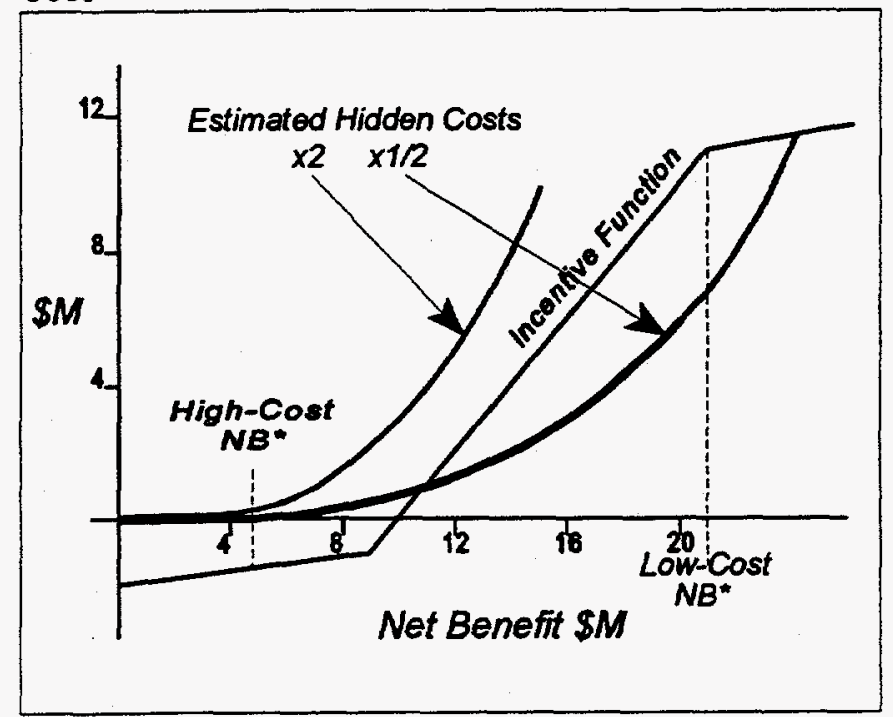
reduction in the slope to the traditional value of 15 percent, which causes the utility to do exactly what it would do in response to the traditional incentive function.

For the low hidden-cost function, the utility would optimize at a point just to the right of the NB value that defines the beginning of the cap. Naturally, this induces the utility to limit its effort to that NB. At this level of effort, its hidden costs are well below the incentive payment, and it earns a considerable profit. In spite of this, the ratepayers are exactly as well off as they would have been with the anticipated (previously analyzed) hidden cost function because for every extra dollar incentive paid, they have received an extra dollar in net benefits. 


\section{A Proposal for Sharing DSM Benefits}

We recommend an approach to ensuring equity based on direct allocation of DSM resource benefits drawing on principles from the traditional cost-allocation literature. Use of such an approach ensures that DSM net benefits are explicitly allocated in accordance to regulatory intent, rather than implicitly (and more crudely) through program participation. We will now describe how such an approach can be carried out when there are three customer classes. Generalization is straightforward.

Assume that there are three classes of customers and three DSM programs, which generate net benefits of $\mathrm{NB}_{1}, \mathrm{NB}_{2}$ and $\mathrm{NB}_{3}$. Assume also that the costs of the utility expenditures for these programs are $C_{1}, C_{2}$, and $C_{3}$. The regulator may wish to ensure that the benefits (e.g., average bill reductions) are distributed differently than would result from a proportional increase in all rates. For instance, the regulator might want to distribute the costs in proportion to the benefits; however, this would reward the class with the largest net benefits the most. A better objective might be to share the benefits in some way that is independent of the DSM programs but depends instead on the size of each class, and perhaps other political considerations. In this case, the regulator would decide on some share of benefit for each class, and these shares could be denoted by $S_{1}, S_{2}$, and $S_{3}$.

As noted, we have been deliberately vague on the definition of the shares because this decision should be made by the regulator based on criteria that need not have anything to do with the economic considerations of this paper. That is, we are concerned here only with demonstrating an efficient method of implementing the regulator's decision, and for that purpose all we require of the share definitions is that $S_{1}+S_{2}+S_{3}=1$. . $^{41}$

The problem is to allocate costs between classes in such a way that the net benefits of customer classes reflect these shares. First, note that the target net benefits for each class are given by:

$$
\text { Target Net Benefits for Class } \begin{aligned}
\mathrm{i} & =S_{i} \cdot[\text { Total Net Benefits }] \\
& =S_{i} \cdot \sum_{j=1}^{3} N B_{j}
\end{aligned}
$$

41 It should be noted that while the classes under consideration can be defined in many ways, we are not contemplating using participant/non-participant status as a criterion. Doing so causes a major shift in the incentive to participate by linking individual rates to the individual's decision to participate. Such a definition of class would require a much deeper analysis than the one presented here. Fortunately, such a definition is not generally contemplated in the argument for disaggregation, so omitting such class definitions does not limit the applicability of the following argument to the disaggregation question. 
where $j$ is a index that runs over the set of classes. Next, consider the net benefit that a class would receive if it did not bear any of the utility's costs of the DSM programs. We will call these "hypothetical" net benefits. If the net benefit generated by the DSM program for class $I$ is a $Q_{i}-C_{P i}-C_{V_{j}}$ (benefit minus participant cost minus utility cost) then the hypothetical net benefit is just $A Q_{i}-C_{P b}$ which is $\mathrm{NB}_{i}+C_{u \text { i. }}$. To bring the "hypothetical" net benefit down (or up) to the target benefit level for each class, a charge equal to the difference must be leveled on each class. The required charge for each class is, therefore:

$$
\begin{aligned}
& \text { Required Charge to Class } \mathbf{i} \\
& =\text { "Hypothetical Net Benefit" - "Target Net Benefit" } \\
& =\left(N B_{i}+C_{U i}\right)-S_{i} \cdot \sum_{j=1}^{3} N B_{j}
\end{aligned}
$$

This means that, in order to assure that each class receives its target share of the total net benefits, they must be assigned a part of the utility's DSM costs that is equal to the net benefit generated by programs delivered to that class, plus the share of DSM costs incurred by those programs, minus the target net benefit for that class. The sum of these charges exactly equals the sum of the utility's DSM costs, so the method is consistent.

To understand the implications of this formula, we now consider an example. First, consider a case with two classes, which, for convenience only, we will call residential (class 1) and commercial (class 2). For the sake of argument, assume that the DSM program is entirely focussed on the commercial class, which accrues all of the net benefit. Also assume that the regulator would like the benefits of DSM shared equally between the two classes for equity's sake. For class 1 we have:

$$
\text { Required Charge to Class } \mathrm{i}=(0)-\frac{1}{2} \cdot N B
$$

where NB is the sum of net benefits, which is, of course, simply the commercial net benefit. Thus, the residential class is allocated a negative amount (implemented through a rate reduction) equal to half of the commercial net benefit. The commercial class, on the other hand, will be charged the following:

$$
\begin{aligned}
\text { Required Charge to Class } \mathrm{i} & =(N B+C U)-\frac{1}{2} \cdot N B \\
& =\frac{1}{2} \cdot N B+C U
\end{aligned}
$$


Thus, the commercial class is allocated all of the utility's program costs plus the cost of transferring half of the net benefits to the residential class. What our recommendation translates to in practice is that in the long run both classes would tend to experience decreases in average bills, but the commercial class participants in the program would not see their bills go down by the full amount implied by using their old tariff. 